\title{
MULTIDIMENSIONAL NMR CHARACTERIZATION OF PERFLUORINATED MONOMER AND ITS PRECURSORS
}

\author{
A Thesis \\ Presented to \\ The Graduate Faculty of The University of Akron \\ In Partial Fulfillment \\ of the Requirements for the Degree \\ Master of Science
}

Bo Zhang

December, 2012 


\section{MULTIDIMENSIONAL NMR CHARACTERIZATION OF PERFLUORINATED MONOMER AND ITS PRECURSORS}

Bo Zhang

Thesis

Approved:

Accepted:

Advisor

Dr. Peter L. Rinaldi

Faculty Reader

Dr. Claire A. Tessier

Department Chair

Dr. Kim C. Calvo
Dean of the College

Dr. Chand Midha

Dean of the Graduate School

Dr. George R. Newkome 


\begin{abstract}
Perfluorinated polymers are extensively studied due to their low absorption in the near-infrared region of spectrum compared to traditional materials. This makes them ideally suited for plastic optical fiber materials (POF). Different types of perfluorinated polymers, such as poly-(perfluoro-2-methylene-4-methyl-1,3-dioxolane) (poly(PFMMD)) and poly-(vinyl-perfluoro-2,4,5-trimethyl-1,3-dioxolane) (poly(VPFMMD)), can serve as alternatives for poly-(1,1,2,4,4,5,5,6,7,7-decafluoro-3-oxa-1,6-heptadiene) (Crytop ${ }^{\circledR}$ ), which is a commonly used fluoropolymer for POF. In order to get a better understanding of the properties of these polymers, it is important to first characterize the structures and purities of their monomer precursors.

In this research, perfluorinated monomer (perfluoro-2-methylene-4,5-dimethyl1,3-dioxolane), its precursor (perfluoro-2,4,5-trimethyl-1,3-dioxolane-2-carboxylic acid), as well as their hydrocarbon precursor (2,4,5-trimethyl-1,3-dioxolane-2-carboxylate), were prepared and studied by 1D- and advanced 2D-NMR techniques. For both perfluorinated compounds, the structures of their possible isomers were proven by 2D-NMR spectroscopy. Due to the large ${ }^{19} \mathrm{~F}$ spectral window, this study used selective versions of the correlation spectroscopy (COSY) and nuclear Overhauser effect spectroscopy (NOESY) experiments to provide better resolution and sensitivity. In addition, a new variation of the gradient heteronuclear single quantum coherence spectroscopy (gHSQC)


sequence was successful for observing two-bond ${ }^{19} \mathrm{~F}-{ }^{13} \mathrm{C}$ correlations. Compared with gradient heteronuclear multiple bond correlation spectroscopy (gHMBC) spectrum, the ${ }^{2} \mathrm{~J}_{\mathrm{FC}}$ gHSQC spectrum is greatly simplified due to the absence of splittings caused by multi-quantum coherence. Quantitative ${ }^{1} \mathrm{H}$ or ${ }^{19} \mathrm{~F}$ 1D-NMR spectroscopy was used to confirm the resonance assignments and to calculate the ratio of isomers. The conformational compositions of perfluorinated compounds and their hydrocarbon precursor support the idea that fluorination by elemental fluorine is a free radical process. 


\section{DEDICATION}

To Zhenhong Zhang and Yawen Bao, my parents, 


\section{ACKNOWLEDGEMENTS}

I would like to express my greatest gratitude to Prof. Peter L. Rinaldi. Thank you for your approval and encouragement for every single step I made. Thank you for letting me make mistakes and telling me that is the best way of learning. Thank you for sharing your own experience with us and making me known of how to be a good scientist and upright person. Thank you for all the suggestions ever made for me; for all your understanding, support and help along the way here today. It is a great honor to have you been my advisor and a really pleasant experience of working in your lab.

I am grateful to Prof. Tessier, for your valuable suggestions on revising my thesis and for your time. I want to give my sincere thanks to Dr.Venkat Dudipala, Mr. Simon Stakleff and Dr. Mingming Guo, Mr. Robert Toma and Dr. Todd Wagler who gave me generous guidance and training on how to do the TA work, especially Dr. Dudipala and Mr. Stakleff's effort on maintaining the NMR instruments, Mr. Robert's effort on installing the practical software. I am also thankful to my groupmates: Linlin Li, Eric Twum, Liladhar Paudel, and Xiaohong Li, I have learnt a lot by watching you set up the NMR experiments. Your kind help and suggestions on dealing with the tasks throughout the graduate study encourage me to be energetic toward work.

I thank Dr. Yoshi Okamoto and Mr. Frantisek Mikes for providing the fluorinated monomer samples and for your help. Many thanks to Dr. Faith Wyzgosky, Dr. Betsy 
McCord and Dr. Peter Fox for your valuable advices on the PVF project.

Finally, I want to express my appreciation to Dr. Changcheng Song and Mrs. Bailing Li for your kind assistance when I first came to US. Many thanks to my friends: Danyang $\mathrm{Wu}$ and Jiang Qiu. I am thankful to my boyfriend Jian Wang, for all your understanding and patience. To my parents, for your love and support throughout my life, you give me the strength of pursuing my dreams. 


\section{TABLE OF CONTENTS}

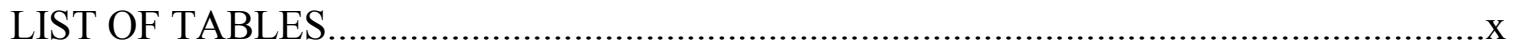

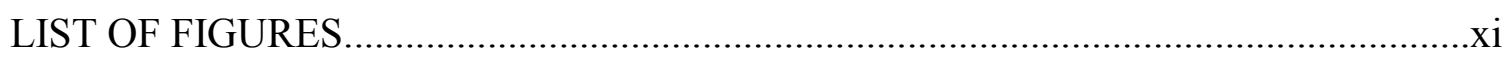

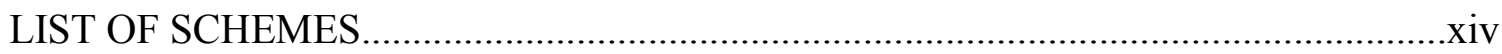

CHAPTER

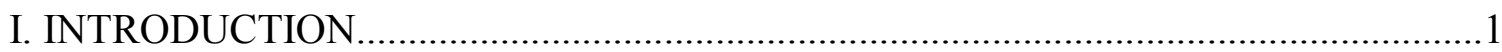

1.1 Objectives.............................................................................................

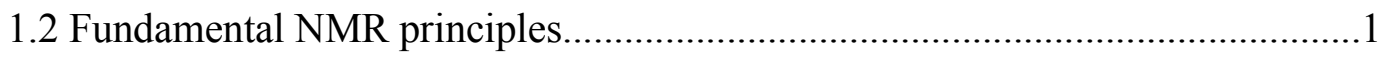

1.2.1 1D-NMR experiments......................................................................

1.2.2 Nuclear Overhauser Effect.............................................................

1.2.3 2D-NMR experiments ...............................................................

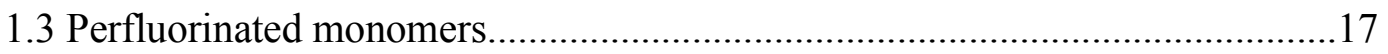

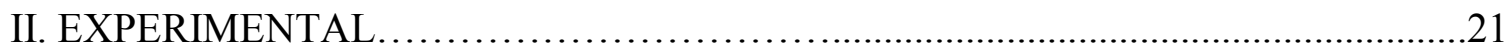

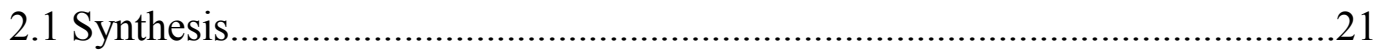

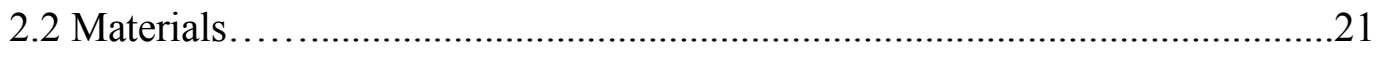

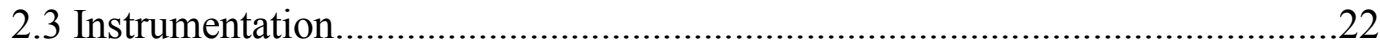

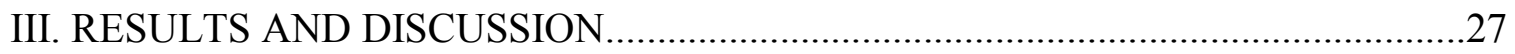

3.1 Hydrocarbon precursor methyl-2,4,5-trimethyl-1,3-dioxolane-2-carboxylate 
3.2 Perfluoro-2,4,5-trimethyl-1,3-dioxolane-2-carboxylic acid (4).............................35

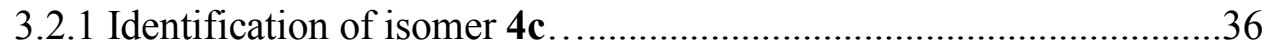

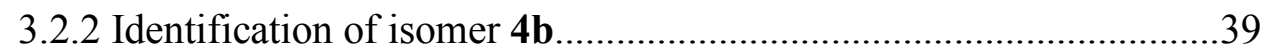

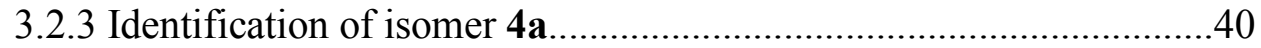

3.2.4 Quantitative ${ }^{19}$ F NMR results...................................................40

3.3 Perfluoro-2-methylene-4,5-dimethyl-1,3-dioxolane (5)..............................43

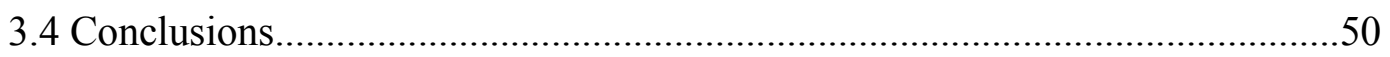

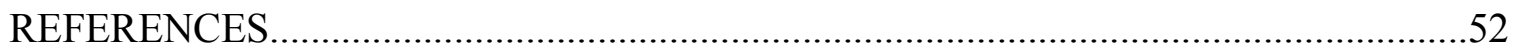




\section{LIST OF TABLES}

Table $\quad$ Page

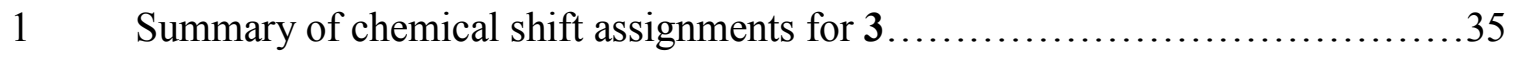

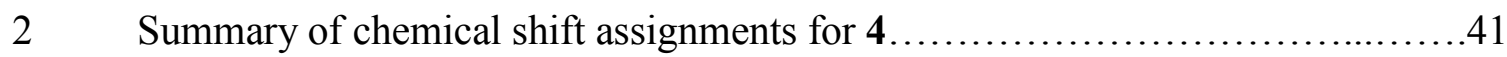

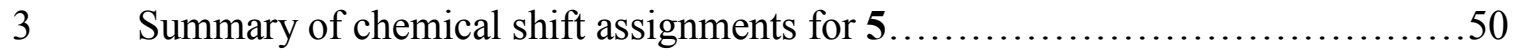




\section{LIST OF FIGURES}

Figure

Page

1 (a) At equilibrium, the orientation of the magnetization $\left(M_{0}\right)$ is along $B_{0}$. (b) When $M_{0}$ is tipped to a certain angle away from the $B_{0}(M)$, there is a component of $M$ in the xy plane. (c) $M$ precesses about the $\mathrm{z}$ axis $\left(B_{0}\right)$ following a decreasing spiral and recovers to $M_{0}$. (d) $T_{1}$ (relaxation of the $\mathrm{z}$ component) and $T_{2}$ (relaxation of the xy component) time constants. .5

2 The pulse program for a simple ${ }^{1} \mathrm{H} 1 \mathrm{D}-\mathrm{NMR}$ experiment.....................6

3 INEPT pulse sequence..............................................

$4 \quad$ Pulse sequence for quantitative ${ }^{13} \mathrm{C}$ NMR experiment.........................

5 Scheme for 2D-data collection and Fourier transformation to produce final 2D-

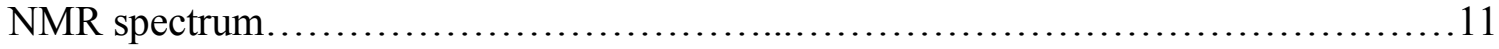

6 Pulse sequence for the COSY experiment............................... 12

$7 \quad$ Pulse program for the NOESY experiment................................13

8 HSQC pulse sequence. Different time periods are: (1) relaxation, (2) first INEPT which transfers proton magnetization to carbon; 3$)$ the evolution time $\left(t_{1}\right)$, where the carbon chemical shift evolves, (4) and with accomplishes INEPT transfer of the magnetization back to protons, refocus the proton magnetization; and (5) the acquisition time $\left(t_{2}\right)$. The $\tau$ delay is set to $1 / 4 \mathrm{~J}$ for the $\mathrm{CH}$ or $\mathrm{CF}$ coupling of intest...................14

$9 \quad \mathrm{HMQC}$ pulse sequence............................................ 15

$10 \quad$ HMBC pulse sequence................................................. 17

11 Configuration isomers of methyl-2,4,5-trimethyl-1,3-dioxolane-2-carboxylate...27

12 Selected regions from the $500 \mathrm{MHz}{ }^{1} \mathrm{H}$ 1D-NMR spectrum of a mixture of isomers of 3: (a) $-\mathrm{CHCH}_{3}$ region, (b) $-\mathrm{CCH}_{3}$ region, (c) $-\mathrm{COOCH}_{3}$ region, and (d) $-\mathrm{CH}$ region....30 
13 Selected region from the $500 \mathrm{MHz}{ }^{1} \mathrm{H}-{ }^{1} \mathrm{H}$ dqCOSY $2 \mathrm{D}-\mathrm{NMR}$ spectrum from a

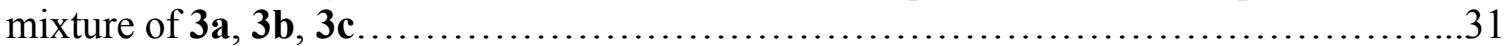

14 Selected region from the $500 \mathrm{MHz}{ }^{1} \mathrm{H}-{ }^{1} \mathrm{H}$ NOESY 2D-NMR spectrum from a

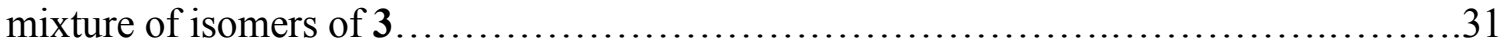

15 Selected region from the $500 \mathrm{MHz}{ }^{1} \mathrm{H}^{-1} \mathrm{H}$ NOESY 2D-NMR spectrum of mixture of 3a, 3b, 3c. 32

$16500 \mathrm{MHz}{ }^{1} \mathrm{H}^{13} \mathrm{C}$ HMBC $2 \mathrm{D}-\mathrm{NMR}$ spectrum of a mixture of $\mathbf{3 a}, \mathbf{3 b}, \mathbf{3} \mathbf{c}$ : (a) full region, (b) expansion of the region in the black circle in a...............................32

17 Selected region from the $500 \mathrm{MHz}{ }^{1} \mathrm{H}-{ }^{13} \mathrm{C}$ gHMBC 2D-NMR spectrum of a mixture of isomers of $\mathbf{3}$ showing correlations between the methyl proton resonances and the ketal carbon resonances. 34

18 Selected region from the quantitative $500 \mathrm{MHz}{ }^{1} \mathrm{H}$ 1D-NMR spectrum from a mixture of $\mathbf{3 a}, \mathbf{3 b}$ and $\mathbf{3 c}$ 34

19 Selected regions from the $470 \mathrm{MHz}{ }^{19} \mathrm{~F}$ 1D-NMR spectrum of perfluoro-2,4,5trimethyl-1,3-dioxolane-2-carboxylic acid (4) showing: (a) the $\mathrm{CF}_{3}$ region, and (b) the $\mathrm{CF}$ region 36

20 Selected region from the $470 \mathrm{MHz}{ }^{19} \mathrm{~F}^{19}{ }^{19} \mathrm{gdqCOSY}$ 2D-NMR spectrum from a mixture of isomers of perfluoro-2,4,5-trimethyl-1,3-dioxolane-2-carboxylic acid (4). .37

21 Selected region from the ${ }^{19} \mathrm{~F}-{ }^{19} \mathrm{~F}$ NOESY $2 \mathrm{D}-\mathrm{NMR}$ spectrum of isomers in $4 \ldots . .38$ $22 \quad 470 \mathrm{MHz}{ }^{19} \mathrm{~F}^{19}{ }^{19} \mathrm{~F}$ selective NOESY NMR spectrum of perfluoro-2,4,5-trimethyl1,3-dioxolane-2-carboxylic acid. 39

$23470 \mathrm{MHz}{ }^{19} \mathrm{~F}^{13} \mathrm{C}$ one bond HSQC 2D-NMR spectrum of isomers in $4\left(\mathrm{CF}_{3}\right.$

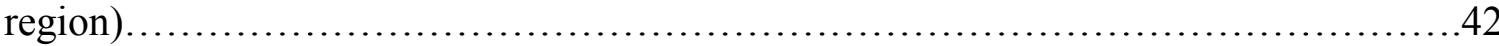

$24470 \mathrm{MHz}{ }^{19} \mathrm{~F}_{-}{ }^{13} \mathrm{C}$ two bond HSQC 2D-NMR spectrum of isomers in $4\left(\mathrm{CF}_{3}\right.$

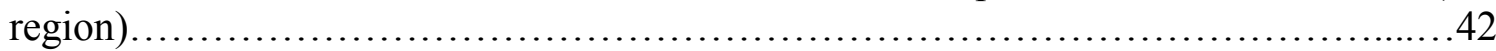

$25470 \mathrm{MHz}{ }^{19} \mathrm{~F}^{13} \mathrm{C}$ two bond 2D-NMR HSQC spectrum of isomers in 4 (CF region).

$26 \quad 470 \mathrm{MHz}{ }^{19} \mathrm{~F}$ 1D-NMR spectrum of isomers of 5 .44

27 Selected regions from the (a) ${ }^{1} \mathrm{~J}_{\mathrm{FC}}$ and (b) ${ }^{2} \mathrm{~J}_{\mathrm{FC}}$ gHSQC NMR spectra of perfluoro- 


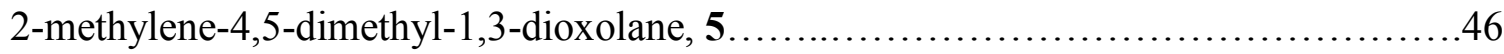

28 Correlations between the $\mathrm{CF}_{2}$ and $\mathrm{CF}$ regions of the $470 \mathrm{MHz}{ }^{19} \mathrm{~F}_{-}{ }^{19} \mathrm{~F}$ selective COSY 2D-NMR spectrum of perfluoro-2-methylene-4,5-dimethyl-1,3-dioxolane, 5.....47

29 Correlations between the $\mathrm{CF}_{3}$ and $\mathrm{CF}$ regions of the $470 \mathrm{MHz}{ }^{19} \mathrm{~F}-{ }^{19} \mathrm{~F}$ selective COSY 2D-NMR spectra of perfluoro-2-methylene-4,5-dimethyl-1,3-dioxolane, 5...........47

30 Selected regions from the $470 \mathrm{MHz}{ }^{19} \mathrm{~F}$ 1D-NMR spectrum of perfluoro-2methylene-4,5-dimethyl-1,3-dioxolane (5) showing: (a) the $\mathrm{CF}_{2} / \mathrm{CF}$ region, and (b) the

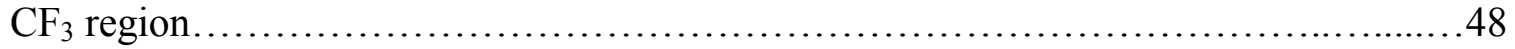

31 Selected regions from the $470 \mathrm{MHz}$ (a, c) ${ }^{1} \mathrm{~J}_{\mathrm{FC}}$, and (b, d) ${ }^{2} \mathrm{~J}_{\mathrm{FC}}$ gHSQC $2 \mathrm{D}-\mathrm{NMR}$ spectra of perfluoro-2-methylene-4,5-dimethyl-1,3-dioxolane (5).....................49 


\section{LIST OF SCHEMES}

Scheme

Page

1 Preparation of perfluoro-2-methylene-4,5-dimethyl-1,3-dioxolane..................18 


\section{CHAPTER I}

\section{INTRODUCTION}

\subsection{Objectives}

The goal of this study is to use the advanced 2D-NMR methods to characterize fluorinated monomer: perfluoro-2-methylene-4,5-dimethyl-1,3-dioxolane, its precursor: perfluoro-2,4,5-trimethyl-1,3-dioxolane-2-carboxylic acid, as well as their hydrocarbon precursor: methyl-2,4,5-trimethyl-1,3-dioxolane-2-carboxylate. Quantitative ${ }^{19} \mathrm{~F}$ and ${ }^{1} \mathrm{H}$ 1D-NMR experiments were conducted to confirm the resonance assignments and to calculate the ratio of isomers. By using NMR to fully characterize the conformational compositions of these perfluorinated compounds and their hydrocarbon precursor, confirmation can be obtained that fluorination by elemental fluorine is a free radical process. These materials serve as the starting materials for the synthesis of fluoropolymers with desirable properties for their optic applications.

\subsection{Fundamental NMR principles}

NMR is an important tool for analyzing small organic compounds, 1

biomolecules, ${ }^{2}$ polymers ${ }^{3,4}$ and dendrimers. ${ }^{5,6}$ Before further discussing the NMR study of these small organic compounds, it is necessary to possess basic knowledge of NMR 
spectroscopy. NMR spectroscopy deals with the alignment of atomic nuclei rather than molecular motion. Every atomic nucleus, which is composed of nucleons (neutrons and protons) with an intrinsic quantum property of spin, has at least one isotope that is associated with a magnetic moment and is active in NMR spectroscopy, if the nucleus overall spin numbers $I$ is not zero. The spin quantum number $I$ can be $0,1 / 2,1,3 / 2$ and etc. The general rules for determining $I$ are: nuclei with odd atomic mass have half integer $I$; nuclei with even atomic mass and with an odd number of neutrons have integer $I$; and nuclei with even atomic mass and with an even number of neutrons have $I=0$. Nuclei having half integer values of $I$ such as ${ }^{1} \mathrm{H},{ }^{13} \mathrm{C},{ }^{19} \mathrm{~F},{ }^{15} \mathrm{~N},{ }^{31} \mathrm{P}$ are commonly used in the NMR spectroscopy. Among these are ${ }^{1} \mathrm{H}$ and ${ }^{13} \mathrm{C}$ which are the most frequently detected nuclei. This research deals exclusively with the nuclei having $I=1 / 2\left({ }^{1} \mathrm{H},{ }^{13} \mathrm{C}\right.$ and ${ }^{19} \mathrm{~F}$ ), which have two possible spin states: spin up and spin down. These two states are degenerate, which means they have the same energy. If such a nucleus is placed in a magnetic field, however, the interaction between its magnetic moment and the external magnetic field splits the two states into a lower energy state $(\alpha$ state, $m=+1 / 2)$ and a higher energy state $(\beta$ state, $m=-1 / 2)$. The energy difference between the two levels is calculated by the equation below:

$$
\Delta \mathrm{E}=(\mathrm{h} \gamma / 2 \pi) B_{0}
$$

where $\mathrm{h}$ is Planck's constant, $\gamma$ is called the magnetogyric ratio, a characteristic constant of each nucleus (a ratio of a particle or system's magnetic dipole moment to angular momentum), and $B_{0}$ is the magnetic field strength. The population distribution of nuclei in the two energy states follows Boltzmann statistics: 


$$
\mathrm{N}_{\alpha} / \mathrm{N}_{\beta}=\mathrm{e}^{-\gamma B 0 \mathrm{~h} / \mathrm{kBT}}
$$

where $\mathrm{k}_{\mathrm{B}}$ is the Boltzmann constant, $\mathrm{T}$ represents the temperature, $\mathrm{N}_{\alpha}$ and $\mathrm{N}_{\beta}$ are the populations of the nuclei in $\alpha$ and $\beta$ states, respectively. As the nuclei preferentially stay in the lower energy state, in which the excess population creates a net magnetization $\left(M_{0}\right)$ along the spinning axis, the magnetization of the remaining nuclei cancel. This net magnetization directly determines how strong the NMR signal could be. At room temperature, however, the thermodynamic energy is much larger than the magnetic energy. Thus the populations of nuclei in the two energy levels are almost equal. To improve the NMR signal to noise ratio, one can decrease the temperature to increase the lower energy state population and hence $M_{0}$. In an extreme case, as the temperature approaches $0 \mathrm{~K}$, all nuclei should stay in the lower energy state; and $M_{0}$ should be maximum. Since it is not practical to perform the experiments at such a low temperature, a more common way to increase $M_{0}$ is to increase the magnetic field $B_{0}$ and keep the temperature fixed. When $B_{0}$ increases, the separation between the two energy states increases (Equation 1), leading to a larger proportion of nuclei in the low energy state, and stronger NMR signals as well. This explains why the NMR researchers are continuously seeking to use higher field instruments.

The second principle to understand magnetic resonance is the behavior of an atomic nucleus in the magnetic field. As discussed previously, more magnetic moments tend to align with the external static magnetic field $\left(B_{0}\right)$ rather than against it, the net magnetization $\left(M_{0}\right)$ vector is aligned along with the $B_{0}$ direction. The NMR detector has a coil to generate an oscillating magnetic field which can tip the nuclear magnetization 
away from its equilibrium into the transverse plane. The process of orienting the nuclear magnetization in the same direction as $B_{0}$ is described by relaxation. After the magnetization is reoriented perpendicular to $B_{0}$, the precession is observable. Such precession is called the Larmor precession and the frequency of Larmor precession is called the Larmor Frequency $(\omega)$, which is described by the following equation:

$$
\omega=\gamma B_{0}
$$

Equation 3 indicates that the Larmor frequency $\omega$ is proportional to the magnetic field $B_{0}$ and the magnetogyric ratio $\gamma$. The same coil not only excites the nuclei, but is also used to detect the signals. As the nuclei precess around the coil, the signal decays with time and gradually returns to its equilibrium state. The signal decay with time is called the free induction decay (FID). The FIDs are Fourier transformed to give the final NMR spectra consisting of a plot of peak intensities versus frequency. Because the adjacent electrons also produce magnetization that is opposed to the external field, the chemical environment of a nucleus specifically determines the effective magnetic field on it. Thus, a shift in resonance frequency is observed in the NMR spectrum that provides the structural information of a molecule.

\subsubsection{D-NMR experiments}

As mentioned above, nuclei with $I=1 / 2$ have two spin states, $m=1 / 2$ and $m=$ $-1 / 2$. The net nuclear magnetization points in the same direction as the external magnetic field $B_{0}$ (Figure 1a). When applying a radio frequency pulse with field perpendicular to $B_{0}$, 
the nuclei in lower energy state can absorb energy $(\Delta \mathrm{E})$ to move to the higher energy level. After the pulse, the nuclei release the absorbed energy and return to the equilibrium state. There are two points we need to pay attention to. The first one is when we apply the radio frequency $(\mathrm{RF})$, such frequency needs to be the same as the precession frequency of the nuclei in order to flip the spins. ${ }^{7}$ Secondly, the angle of the flipped nuclear magnetization is decided by the length of RF pulses. Since the receiver is on the transverse plane (xy plane), only the projection of $M_{0}$ on xy plane can be detected (Figure 1b). With time, the magnetization $M$ gradually relaxes back to its original state with $M_{0}$ aligned along $B_{0}$ (Figure 1c).

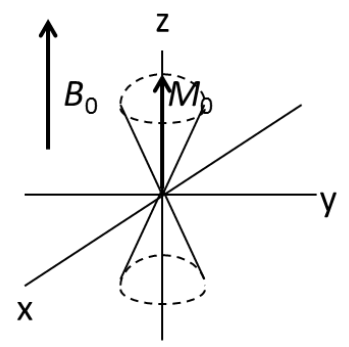

(a)

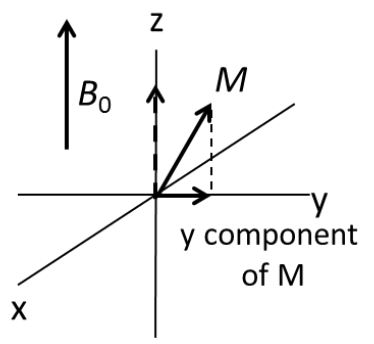

(b)

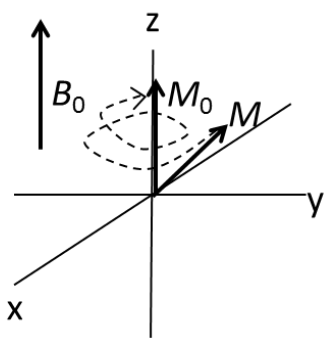

(c)

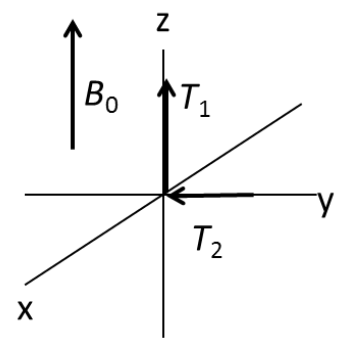

(d)

Figure 1. (a) At equilibrium, the orientation of the magnetization $\left(M_{0}\right)$ is along $B_{0}$. (b) When $M_{0}$ is tipped to a certain angle away from the $B_{0}(M)$, there is a component of $M$ in the xy plane. (c) $M$ precesses about the $\mathrm{z}$ axis $\left(B_{0}\right)$ following a decreasing spiral and recovers to $M_{0}$. (d) $T_{1}$ (relaxation of the $\mathrm{z}$ component) and $T_{2}$ (relaxation of the xy component) time constants.

There are two relaxation processes involved in the return of $M_{0}$ to the $\mathrm{z}$ axis, these are spin-lattice ( $T_{1}$ relaxation) and spin-spin $\left(T_{2}\right.$ relaxation) processes. In Figure $1 \mathrm{~d}, T_{1}$ relaxation reflects the interactions between the excited nuclei and the surrounding lattice, 
which determines the time required for the $\mathrm{z}$ component to return to $M_{0}$, whereas $T_{2}$ relaxation indicates the interactions between the precessing nuclei which cause the line broadening. $T_{2}$ is the time constant, which determines the return of the xy component of $M$ to zero.

A simple pulse program describes the basic 1D-NMR experiment is shown in Figure 2. It is composed of preparation and detection periods. During the preparation period, the observed nuclei return to their equilibrium state, $M_{0}$. This is followed by an RF pulse $(\theta)$, which flips this magnetization to produce a component of the magnetization $M$ in the xy plane. During the detection period, the precessing magnetization is detected. The decaying signal acquired at this point is a time domain signal, after Fourier transform, the signal is converted into the frequency domain. By simply repeating the experiments $n$ times, a better signal to noise ratio can be obtained due to signal averaging. Other 1DNMR experiments such as INEPT, ${ }^{8} \mathrm{APT}^{9,10}$ and $\mathrm{DEPT}^{11}$ have more complicated pulse sequences, which will be discussed in the next section.

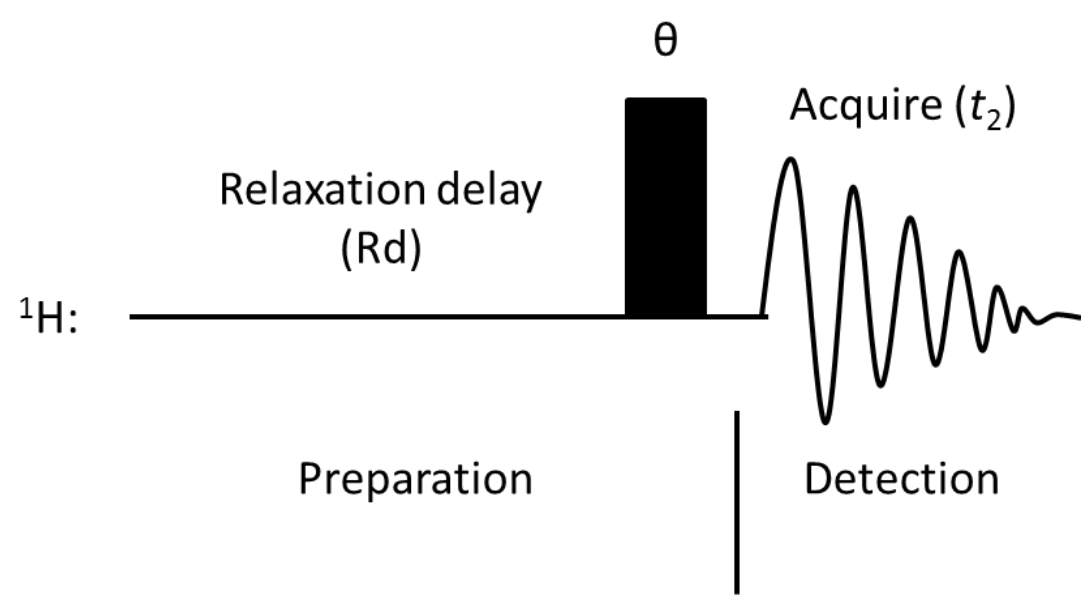

Figure 2. The pulse program for a simple ${ }^{1} \mathrm{H}$ 1D-NMR experiment. 


\subsubsection{Nuclear Overhauser Effect}

When the nuclei A and B are near to each other in space, the two magnetic spins interact. If one of the nuclei $\mathrm{A}$ is irradiated with its own resonance frequency $\left(v_{2}\right)$, this results in signal increases of the nuclei B which are detected after a non-selective pulse. The reason for such signal enhancement is that as nuclei A are saturated by the second RF field, they transfer their energy to nuclei B by cross-relaxation. This effect is defined as the nuclear Overhauser effect (NOE). There are homonucleur and heteronuclear NOEs. For example, the ${ }^{1} \mathrm{H} 1 \mathrm{D}$ homonuclear NOE difference experiment ${ }^{12}$ is used to identify the nearby nuclei over a distance up to about $5 \AA$. This experiment is useful to distinguish different isomers. However, the normal enhancement obtained is less than $50 \%$ in homonuclear NOE experiments, which is much less than that of the heteronuclear NOE. Take the ${ }^{13} \mathrm{C}$ spectra as an example, the ${ }^{13} \mathrm{C}$ atoms attached to protons will have a greater enhancement from proton decoupling. The maximum enhancement factor is calculated by $\gamma_{\mathrm{H}} / 2 \gamma_{\mathrm{C}}$, which is 1.98 . So the enhanced ${ }^{13} \mathrm{C}$ signals are up to 2.98 times as intense as the coupled signals without NOE.

The INEPT ${ }^{8}$ (Insensitive Nuclei Enhanced by Polarization Transfer) sequence is based on population transfer and is a fundamental element of many $2 \mathrm{D}-{ }^{13}$ and 3D-NMR experiments. ${ }^{14}$ It transfers the polarization difference from protons to other low gamma nuclei such as ${ }^{13} \mathrm{C}$ (Figure 3), in order to acquire stronger signals of the low gamma nuclei. To better understand the pulse sequence, here is one example about how the polarization transfer occurs between ${ }^{1} \mathrm{H}-{ }^{13} \mathrm{C}$ coupled nuclei in an INEPT pulse sequence. First, the relaxation delay lets the net magnetization of the ${ }^{1} \mathrm{H}$ nuclei align with the 
external magnetic field. Then the first $90^{\circ}$ pulse is applied, which tips the magnetization of protons into the xy plane. After a $\tau$ delay $(\tau=1 / 4 \mathrm{~J})$, the pair of $180^{\circ}$ pulses are applied on both proton and carbon channels to refocus field inhomogeneity and chemical shift; the heteronuclear coupling interactions are left unaffected. After the second evolution time $\tau$, the two ${ }^{1} \mathrm{H}$ magnetization components from heteronuclear couplings are antiphase along $\mathrm{x}$ axis. The final pair of $90^{\circ}$ pulses inverts the proton populations and transfers the polarization to carbon nuclei, which eventually leads to a $\gamma_{\mathrm{H}} / \gamma_{\mathrm{C}}$ increase in the $\mathrm{X}$ nucleus peak intensity, the $90^{\circ}$ pulse on the $\mathrm{X}$ channel flips the ${ }^{13} \mathrm{C}$ magnetization into the xy plane for detection.

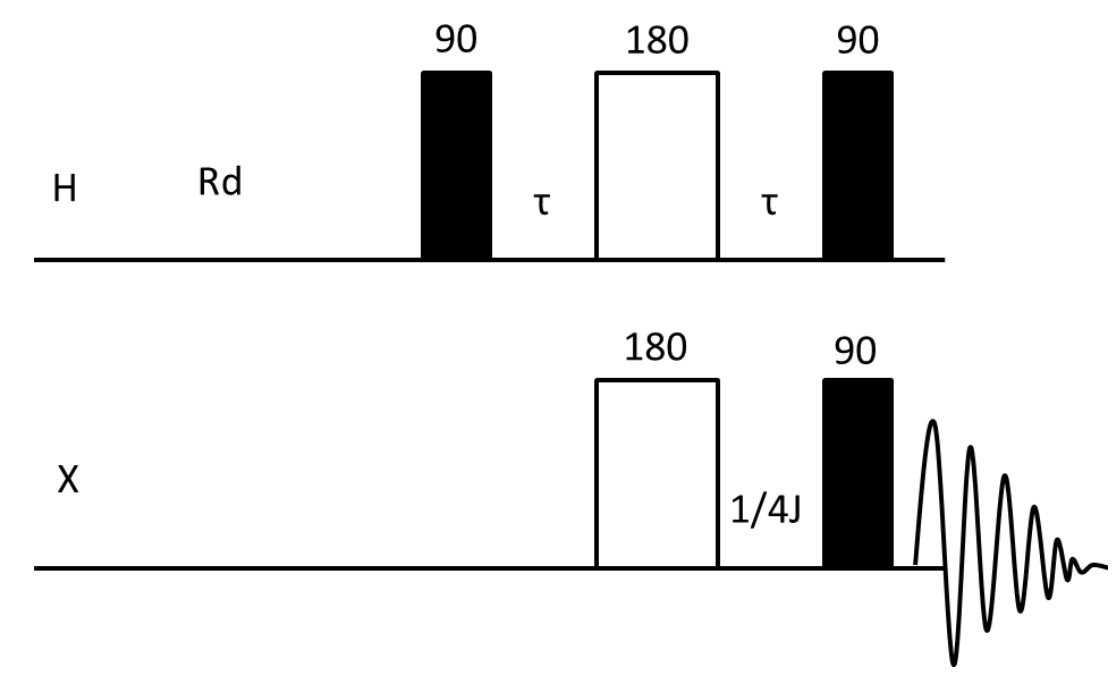

Figure 3. INEPT pulse sequence.

In the qualitative ${ }^{13} \mathrm{C}$ NMR experiments, ${ }^{1} \mathrm{H}$ nuclei are decoupled to get simpler and higher intensity ${ }^{13} \mathrm{C}$ signals. When quantitative ${ }^{13} \mathrm{C}$ NMR spectra are required, both 
the carbon $T_{1}$ and NOE are the important factors to consider in obtaining reliable quantitative data. The nuclei in larger molecules in solution normally have shorter $T_{1} \mathrm{~S}$ compared to those of the smaller molecules. Different parts in the polymer also have different $T_{1} \mathrm{~S}$. Chain ends and short chain branches tend to have longer $T_{1} \mathrm{~S}$ than the main chain due to higher mobility. ${ }^{15}$ The relaxation time is set according to the $T_{1}$ 's, $5 \times T_{1}$ time is required to allow the magnetization recover to the $\mathrm{z}$ axis. The NOE, described earlier, for enhancing the intensity of carbon signals, should be avoided when acquiring a quantitative ${ }^{13} \mathrm{C}$ spectrum since the carbon signals are differentially enhanced depending on local motions and the distances to nearby protons. In Figure 4, the pulse sequence for a gated decoupling experiment is shown, when the protons are decoupled during the acquisition time, which is too short of a period to build up NOE. The final ${ }^{13} \mathrm{C}$ spectrum is still decoupled and produces quantitative information from decoupled singlets peaks.

The $\mathrm{APT}^{9}$ (attached proton test) experiment is a kind of ${ }^{13} \mathrm{C} 1 \mathrm{D}-\mathrm{NMR}$ experiment used to distinguish among the resonances of $\mathrm{C}, \mathrm{CH}, \mathrm{CH}_{2}$ and $\mathrm{CH}_{3}$ carbons, by adjusting the delays according to the coupling patterns of quaternary, methine, methylene and methyl groups. The ${ }^{13} \mathrm{C}$ spectrum is obtained in which quaternary and methylene carbons are positive and methine and methyl carbons are inverted. A more useful experiment called DEPT ${ }^{11}$ (distortion enhancement by polarization transfer), is more popular and is used to distinguish the $\mathrm{CH}, \mathrm{CH}_{2}$, and $\mathrm{CH}_{3}$ groups. Only carbon atoms attached to protons are detected in the DEPT experiment. After adding or subtracting the spectra, $\mathrm{CH}_{3}, \mathrm{CH}_{2}$ and $\mathrm{CH}$ only spectra can be produced. 


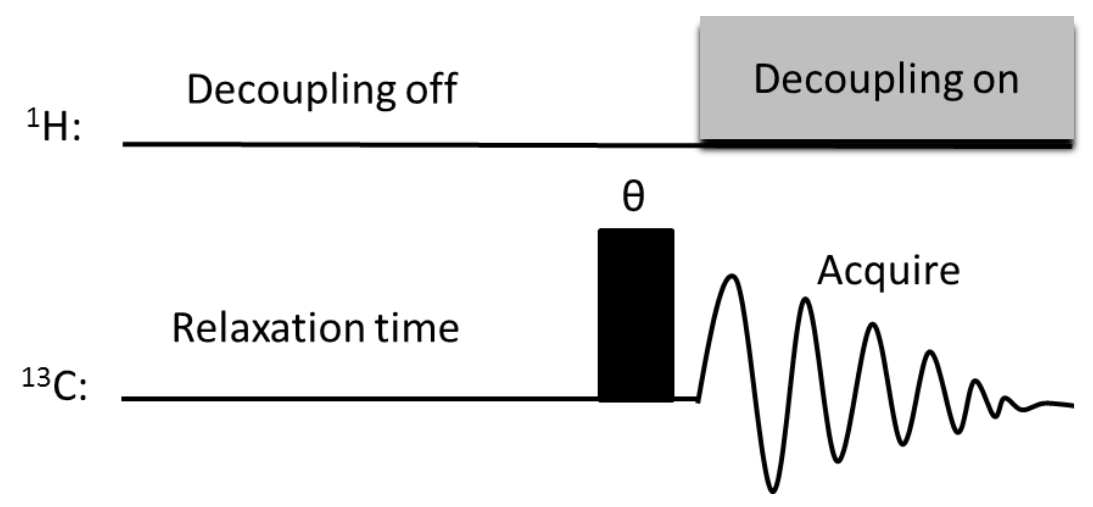

Figure 4. Pulse sequence for quantitative ${ }^{13} \mathrm{C}$ NMR experiment.

\subsubsection{D-NMR experiments}

In ${ }^{1} \mathrm{H}$ 1D-NMR spectra, all the resonances are spread over ca. $10 \mathrm{ppm}$ range. When the structure of compound is complicated, some resonances may overlap, which makes their assignments extremely difficult. Homonuclear 2D-NMR experiments such as $\operatorname{COSY}^{16,17}$ (correlation spectroscopy), TOCSY ${ }^{18}$ (total correlation spectroscopy) and NOESY ${ }^{19,20}$ (nuclear Overhauser enhancement spectroscopy) can provide better dispersion of the resonances by dispersing them into a second dimension. On the other hand, in ${ }^{13} \mathrm{C}$ detected NMR experiments, the carbon sensitivity is considerably lower than in ${ }^{1} \mathrm{H}$ detected NMR experiments, requiring longer signal averaging times and higher sample concentration. The 2D-NMR experiments like HSQC, ${ }^{13} \mathrm{HMQC}^{21}$ and $\mathrm{HMBC}^{22}$ are used to detect carbon indirectly, providing better sensitivity.

All 2D-NMR experiment pulse programs can be described by four periods: preparation, evolution, mixing and acquisition (Figure 5). The preparation period is similar to that in the 1D-NMR experiment. The relaxation delay provides time for the 
nuclear spins to recover to equilibrium after last acquisition. Then a single $90^{\circ}$ pulse or a cluster of pulses are applied to tip the magnetization into the transverse plane. In the evolution period $\left(t_{1}\right)$, the magnetization evolves by gradually increasing the $t_{1}$ delay, which allows building up of the NMR coherence to be modulated in indirectly detected dimension $\left(f_{1}\right)$. In the mixing period, one or more pulses are used to transfer the NMR coherence among nuclei. During the acquisition period, the decaying magnetization in the xy plane is detected. The final data set is Fourier transformed with respect to $t_{2}$ and then $t_{1}$ to produce the final spectrum with intensity plotted versus $v_{1}$ and $v_{2}$.

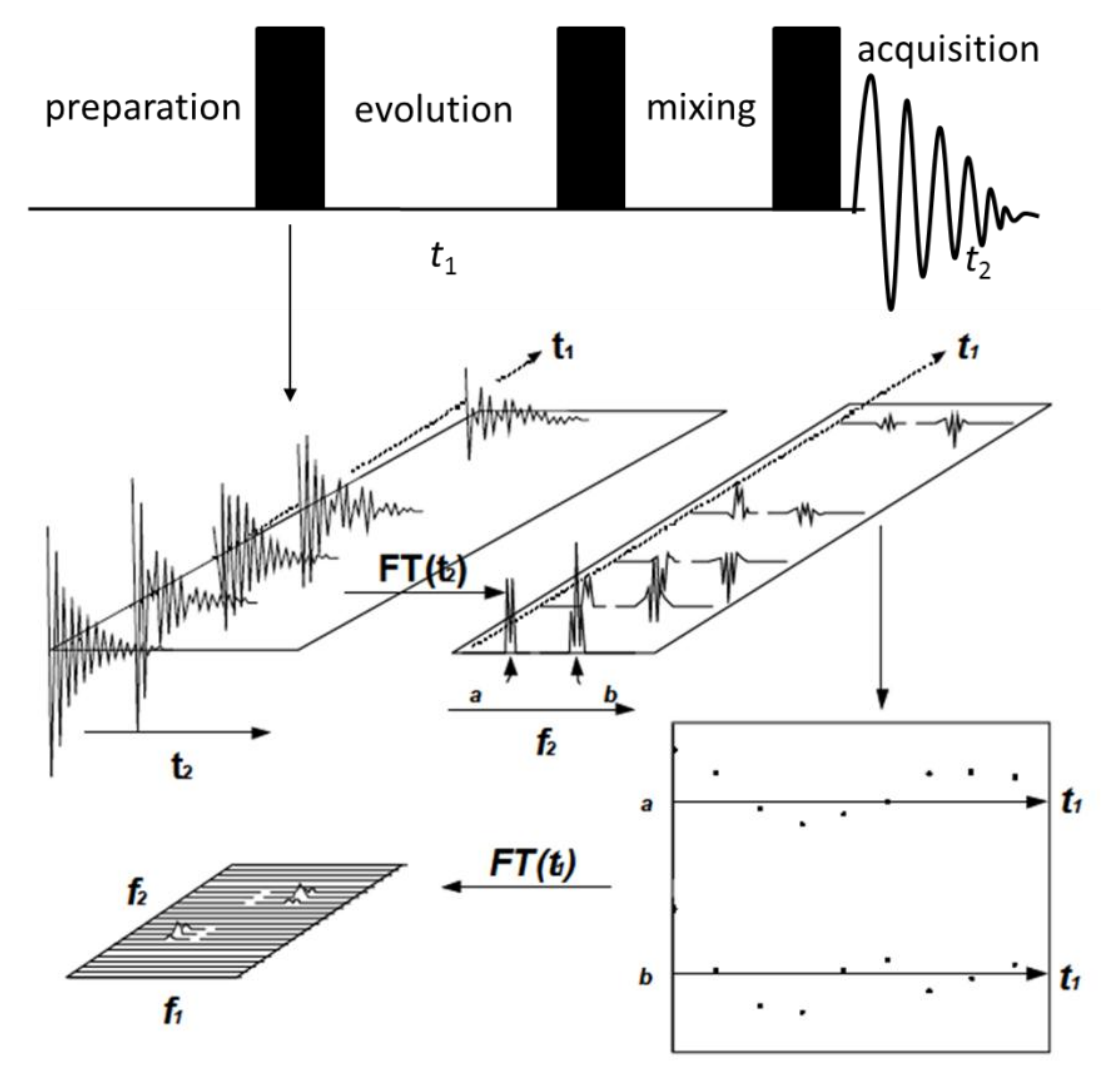

Figure 5. Scheme for 2D-data collection and Fourier transformation to produce final 2DNMR spectrum. ${ }^{23}$ 
The $\operatorname{COSY}^{16,17}$ (correlation spectroscopy) experiment is the simplest 2D-NMR experiment, and is also one of the most useful (Figure 6). After the relaxation delay, the first $90^{\circ}$ pulse flips the magnetization into the xy plane. During the $t_{1}$ evolution time, the variable $t_{1}$ delay increments generate chemical shift and $\mathrm{J}$ modulation in the second dimension $\left(f_{1}\right.$ dimension). At the end of evolution period, the second $90^{\circ}$ pulse mixes the energy states of the nuclei, transferring magnetization between coupled spins. Signals are acquired during the $t_{2}$ period. Fourier transformation produces the final spectrum with diagonal peaks at the shift of nuclei, and the off-diagonal cross peaks that indicate the magnetization exchanges by scalar coupling between nuclei. The resonance assignments can be made by identifying the coupled protons. Whereas the COSY spectrum shows the nuclear correlations through bonds, the magnitude of the correlations depends on the scalar couplings. The larger the coupling constants will generate the stronger observed correlation. NOESY ${ }^{19}$ (nuclear Overhauser effect spectroscopy), on the other hand, reveals the interactions between protons through space $(<5 \AA)$.

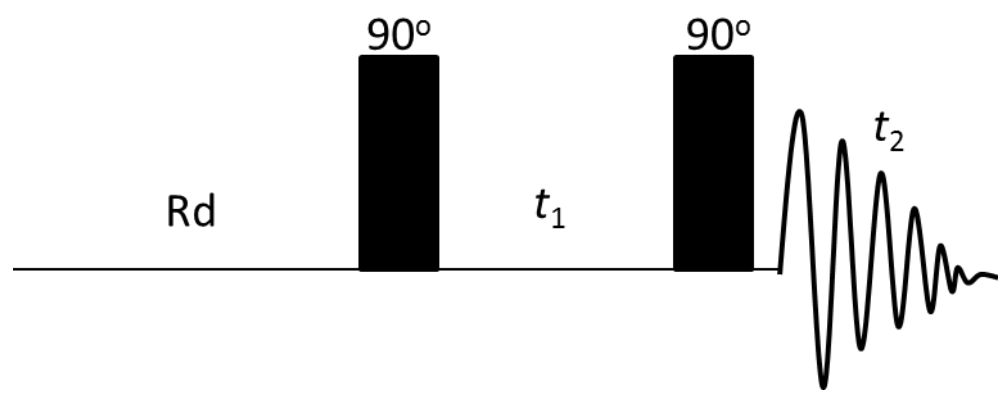

Figure 6. Pulse sequence for the COSY experiment. 
The NOESY pulse program is described in Figure 7. As in the COSY experiment, the pulse sequence starts with a $90^{\circ}$ pulse followed by $t_{1}$ (evolution time). The second $90^{\circ}$ pulse transmits some of the magnetization in the xy plane back to z-axis. During the mixing time, the non-equilibrium nuclear magnetization is transferred among nuclei by dipole-dipole interactions (relaxation), which was discussed earlier as NOE (nuclear Overhauser effect). After the mixing time, the third $90^{\circ}$ pulse is applied to tip the magnetization into the transverse plane to be detected. The spectra look very much like the COSY NMR spectra, but with cross peaks showing the correlations based on the presence of through space $(<5 \AA)$ interactions. The mixing time is adjusted depending on the molecule's size. The mixing time should be about $80 \%$ of the relaxation time. For larger molecules, the mixing time should be shorter to avoid spin-diffusion problems.

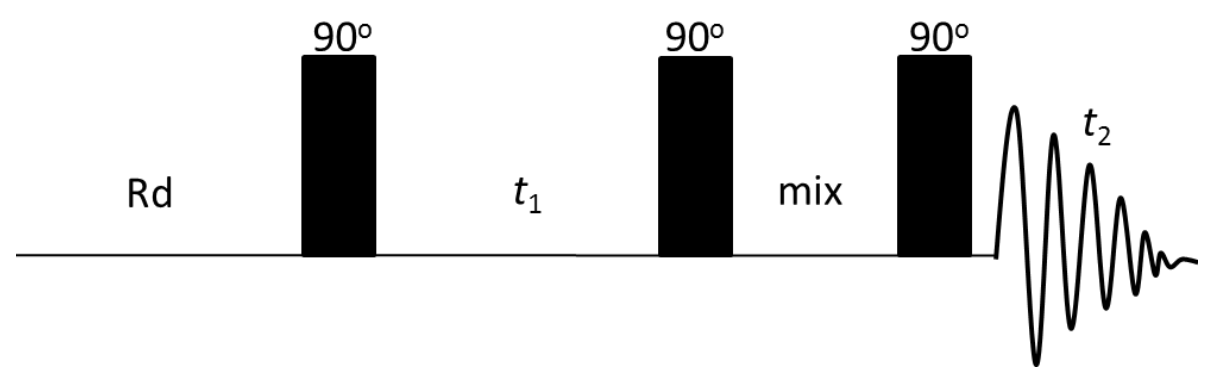

Figure 7. Pulse program for the NOESY experiment.

In addition to the homonuclear 2D-NMR experiments, there are heteronuclear experiments like $\mathrm{HSQC},{ }^{13} \mathrm{HMBC}^{22}$ and $\mathrm{HMQC}^{21}$. HSQC (heteronuclear single quantum correlation) is normally used to detect the proton-carbon correlations through bond(s). Traditionally the HSQC spectra give information about one bond ${ }^{1} \mathrm{H}-{ }^{13} \mathrm{C}$ correlations. In 
recent years, it has been shown that HSQC experiments can selectively show the two bond ${ }^{19} \mathrm{~F}-{ }^{13} \mathrm{C}$ correlations. ${ }^{24}$ The reason is that fluorinated molecules have both large ${ }^{1} \mathrm{~J}_{\mathrm{FC}}$ and ${ }^{2} \mathrm{~J}_{\mathrm{FC}}$ couplings that fall in distinct ranges $\left({ }^{1} \mathrm{~J}_{\mathrm{FC}}=150-350 \mathrm{~Hz}\right.$ and $\left.{ }^{2} \mathrm{~J}_{\mathrm{FC}}=10-100 \mathrm{~Hz}\right)$. The ${ }^{19} \mathrm{~F}$ nucleus is also highly abundance $(100 \%)$ and has high NMR receptivity, thus the ${ }^{19} \mathrm{~F}-{ }^{13} \mathrm{C}$ two-bond correlations can be observed in the ${ }^{19} \mathrm{~F}-{ }^{13} \mathrm{C}$ HSQC experiments.

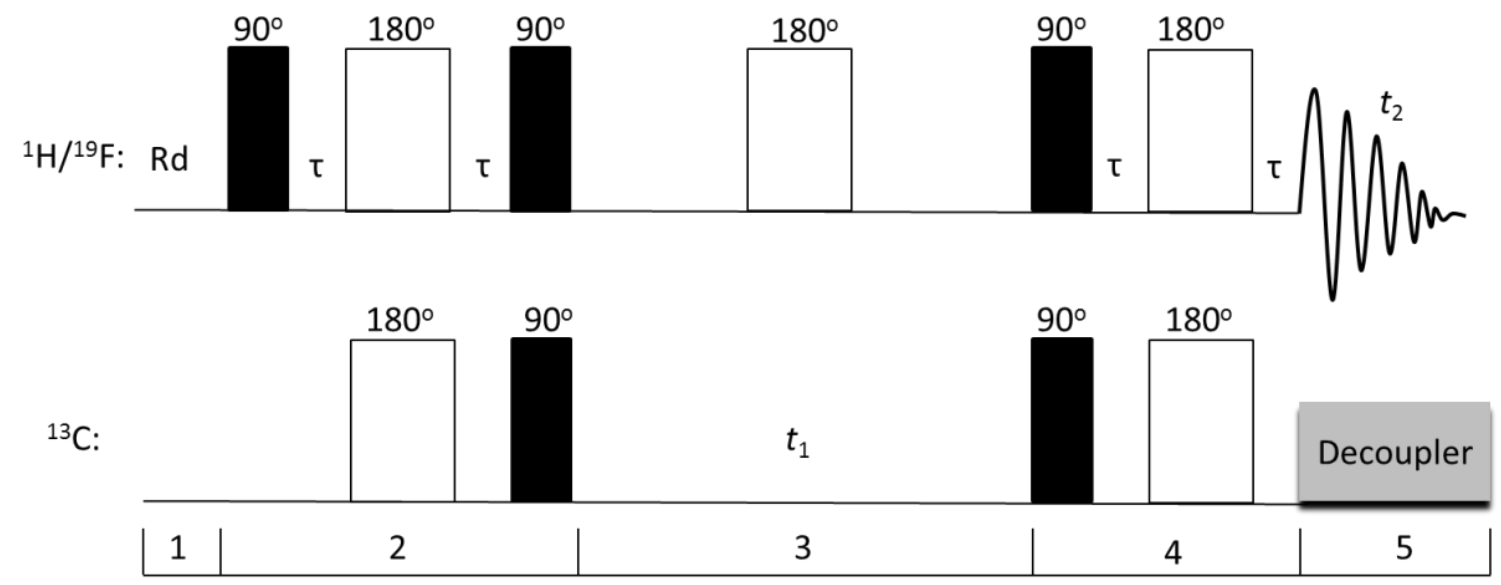

Figure 8. HSQC pulse sequence. Different time periods are: (1) relaxation; (2) first INEPT which transfers proton magnetization to carbon; (3) the evolution time $\left(t_{1}\right)$, where the carbon chemical shift evolves, (4) and with accomplishes INEPT transfer of the magnetization back to protons; refocus the proton magnetization; and (5) the acquisition time $\left(t_{2}\right)$. The $\tau$ delay is set to $1 / 4 \mathrm{~J}$ for the $\mathrm{CH}$ or $\mathrm{CF}$ coupling of interest.

Figure 8 shows the HSQC pulse sequence. Taking a closer look at the pulse program, it can be seen that the pulse sequence is composed of two sets of INEPT ${ }^{8}$ sequences. The first INEPT sequence transfers the proton anti-phase magnetization to the attached carbon nuclei. The carbon chemical shift then evolves during the evolution time $t_{1}$, the $180^{\circ}$ pulse in the middle of the evolution time applied to the proton nuclei eliminates the proton-carbon couplings. The last pair of $90^{\circ}$ pulses at the end of period 3 
also serves to effect reverse INEPT to transfer magnetization back to the detected nuclei. Following the pair of $90^{\circ}$ pulses on the proton and carbon channels, the anti-phase magnetization created during period 2 is refocused during period 4. Proton signals are directly detected during the $t_{2}$ period with carbon decoupling.

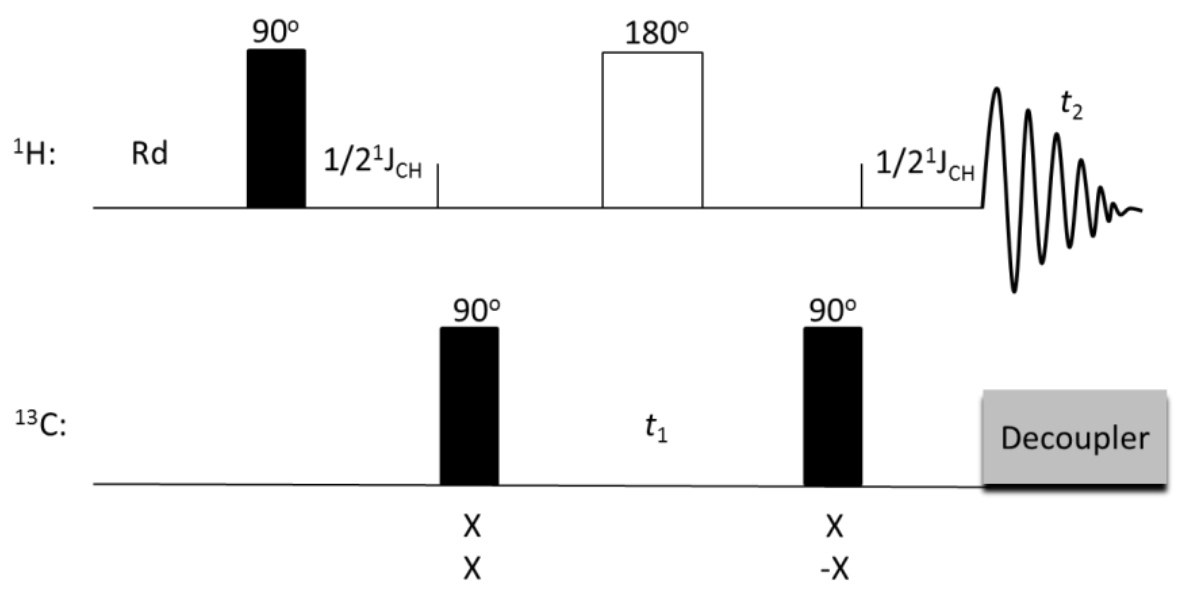

Figure 9. HMQC pulse sequence.

The HMQC ${ }^{21}$ (Heteronuclear Multiple Quantum Correlation) experiment gives correlation information between resonances of protons and their directly attached carbons through J coupling (scalar coupling). This experiment eliminates the ${ }^{1} \mathrm{H}-{ }^{12} \mathrm{C}$ correlations by changing the phase of the two $90^{\circ}$ pulses on the carbon channel (Figure 9). By subtracting the signals from alternate transients, the spectrum selectively leaves the signals of ${ }^{1} \mathrm{H}-{ }^{13} \mathrm{C}$ coupled signals. The evolution time $\left(t_{1}\right)$ provides ${ }^{13} \mathrm{C}$ chemical shift modulation in the indirectly detected dimension $\left(f_{1}\right)$. In the HMQC pulse sequence (Figure 9), the first $90^{\circ}$ pulse on protons generates transverse ${ }^{1} \mathrm{H}$ magnetization in the $\mathrm{xy}$ 
plane, following the delay (1/2J) anti-phase proton magnetization with respect to $\mathrm{J}_{\mathrm{CH}}$ coupling is produced. The first $90^{\circ}$ pulse on carbon nuclei produces multiple quantum coherence, which evolves during $t_{1}$ period. The $180^{\circ}$ pulse in the middle of $t_{1}$ refocuses the proton-carbon coupling and proton chemical shift. At the end of the evolution period, the second $90^{\circ}$ pulse on carbon transfers the coherence back to protons and the single quantum anti-phase proton magnetization is left. After the $1 / 2 \mathrm{~J}$ delay, the anti-phase magnetization is refocused for detection. By alternating the phase of the second $90^{\circ}$ pulse on the carbon channel, the goal of cancelling the ${ }^{1} \mathrm{H}-{ }^{12} \mathrm{C}$ signals is achieved. During the acquisition period, the carbon channel decoupler is turned on to decouple ${ }^{13} \mathrm{C}$. One complication of the HMQC experiment is that $\mathrm{J}_{\mathrm{HH}}$ homonuclear coupling in the $t_{1}$ period contributes to the splittings in the $t_{1}$ dimension leading to complex multiplet patterns and reduced signal to noise levels compared to HSQC 2D-NMR spectra.

The HMBC (heteronuclear multiple bond correlation) experiment detects correlations from long range coupling through bonds (Figure 10). The one-bond ${ }^{1} \mathrm{H}-{ }^{13} \mathrm{C}$ coupling is eliminated by changing the phase of the first $90^{\circ}$ pulse on the carbon channel, which generates the large one bond multi quantum magnetization. After a $\tau$ delay $(\tau=1 / 2$ ${ }^{n} J_{C H}$ and is set based on long range coupling constant), the second $90^{\circ}$ pulse applied to the carbon nuclei creates the multiple quantum coherence from long range coupling. During the evolution period, the carbon multiple quantum coherence evolves and the $180^{\circ}$ pulse on the proton channel refocuses the heteronuclear couplings and the proton chemical shifts. The final $90^{\circ}$ pulse on the carbon channel transmits the coherence back to single quantum proton magnetization. The HMBC experiment is conducted without carbon 
decoupling, thus both the heteronuclear and homonucleur couplings can be observed in this experiment.

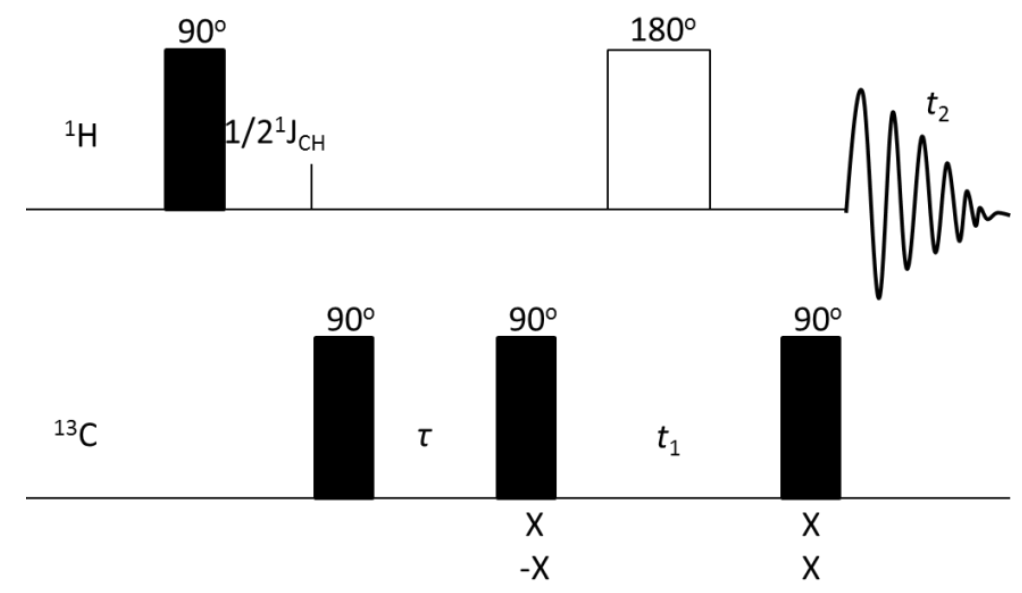

Figure 10. HMBC pulse sequence.

\subsection{Perfluorinated monomers}

Perfluorinated and partially fluorinated polymers and copolymers generally exhibit remarkable properties, such as excellent chemical and thermal stability, good mechanical properties, excellent near infrared transparency, and low absorption losses at most wavelengths. ${ }^{25}$ In particular, perfluorodioxole-based polymers, like the copolymers of 2,2-bis(trifluoromethyl)-4,5-difluoro-1,3-dioxole and tetrafluoroethylene well known as Teflon ${ }^{\circledR} \mathrm{AF}^{26,27}$ by DuPont, and Cytop ${ }^{\circledR 2}$ by Asahi Glass Company, have received close attention in the development of advanced materials. Many other classes of fluorinated polymers are suitable for different high performance applications. 
For some time there has been much effort concentrated on the preparation of perfluorinated or partially fluorinated polymers suitable for optical applications, e.g. for preparation of plastic optical fibers (POF). ${ }^{29}$ Prof. Y. Okamoto's group ${ }^{30,31,32}$ have focused on the preparation of 4- and/or 4,5-disubstituted-2-methylene-1,3-dioxolanes. Their polymers are amorphous, optically transparent in the visible and near infrared region of spectrum and have high glass transition temperatures $\left(135-185^{\circ} \mathrm{C}\right)$. Perfluoro-2methylene-4,5-dimethyl-1,3-dioxolane (5) was prepared via the condensation reaction of methyl pyruvate with 2,3-butanediol. The 1,3-dioxolane derivative was fluorinated in a fluorinated solvent by elemental fluorine diluted with inert $\mathrm{N}_{2}$ gas. The potassium perfluoro-2,4,5-trimethyl-1,3-carboxylate (4) was then decarboxylated (Scheme 1).

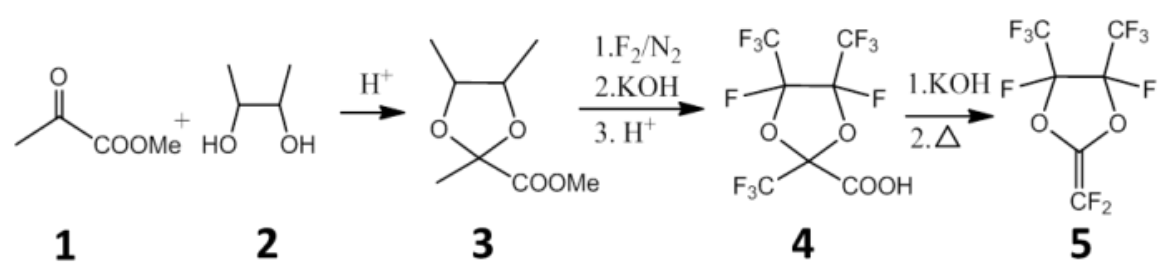

Scheme 1. Preparation of perfluoro-2-methylene-4,5-dimethyl-1,3-dioxolane monomer.

It is obvious that in the case of perfluorinated-4,5-disubstituted-2-methylene-1,3dioxolanes (5), the properties of the polymers will depend not only on the type of substituents, but also on the mutual position of the substituents in the 1,3-dioxolane ring. In this thesis, the detailed NMR characterizations of perfluorinated 2-methylene-4,5dimethyl-1,3-dioxolane (5) monomer, and its perfluorinated and hydrocarbon precursors $(\mathbf{4}$ and $\mathbf{3})$ are described. 
Due to the existence of different isomers and complicated splitting patterns, it is difficult to assign the resonances unambiguously simply based on the 1D-NMR spectra. 2D-NMR is a powerful tool for structural characterization of both small molecules and polymers. By choosing a desired coherence pathway, a 2D-NMR experiment can be devised to provide specific structural information. COSY ${ }^{16,17}$ and NOESY ${ }^{19,20}$ can provide proton-proton (or fluorine-fluorine) correlations via $\mathrm{J}$ couplings and through space interactions, respectively. The ${ }^{1} \mathrm{H}\left\{{ }^{13} \mathrm{C}\right\}$ gradient heteronuclear single quantum coherence (gHSQC) $)^{13}$ and gradient heteronuclear multi-bond correlation $(\mathrm{gHMBC})^{22}$ can provide one-bond and multiple-bond (2- or 3-bond) correlations, respectively, between ${ }^{1} \mathrm{H}$ and ${ }^{13} \mathrm{C}$.

Considerable work can be found using ${ }^{1} \mathrm{H}$-detected 2D-NMR for structural characterization. However, the use of ${ }^{19} \mathrm{~F}$ detected 2D-NMR has not been so popular. Battiste and Newmark have published an excellent review on applications of ${ }^{19} \mathrm{~F}$ multidimensional $\mathrm{NMR}^{50}$ and more recently, Rinaldi et al. ${ }^{4}$ have published a review on applications of NMR in the study of fluoropolymers. Battiste et al. ${ }^{33}$ used ${ }^{19} \mathrm{~F}-{ }^{19} \mathrm{~F}$ NOESY to study the cis and trans isomers in perfluoro-1,3-dimethyl-cyclohexane. In Wormald's ${ }^{34}$ work, ${ }^{19} \mathrm{~F}-{ }^{1} \mathrm{H}$ HETCOR and ${ }^{19} \mathrm{~F}-{ }^{19} \mathrm{~F}$ COSY were used to identify the defect units, short chain branching, and chain ends in vinylidene fluoride (VDF) telomer. Li's ${ }^{24}$ study showed that selective COSY spectra of fluorinated polymer have better resolution compared with the conventional COSY spectra. Newmark's ${ }^{35}$ work reveals the advantages of the gHSQC sequence over gHMQC to detect one bond ${ }^{19} \mathrm{~F}-{ }^{13} \mathrm{C}$ correlations. The gHMBC experiment is basically a modified version of $\mathrm{gHMQC}^{36}$ (gradient assisted 
heteronuclear multiple quantum coherence) sequence, thus suffering similar problems. ${ }^{37}$ $\mathrm{Li}^{49}$ also proved that a ${ }^{2} \mathrm{~J}_{\mathrm{FC}}$ gHSQC experiment is more effective than a gHMBC experiment to study two-bond correlations between ${ }^{19} \mathrm{~F}$ and ${ }^{13} \mathrm{C}$.

Several papers have been found describing NMR studies of the materials studied in this work. Liu ${ }^{31}$ provided the ${ }^{1} \mathrm{H}$ and ${ }^{19} \mathrm{~F}$ 1D-NMR data of 3, 4 and 5. A similar fluorinated monomer was studied using 2D-HMQC NMR by Suzuki and Yamamoto. ${ }^{38}$ They assigned ${ }^{19} \mathrm{~F}$ resonances of difluoromethylene-4,4,5-trifluoro-5-trifluoromethyl-1,3dioxolane.

In this study, selective versions of COSY and NOESY experiments were utilized to excite the target windows for observing useful correlation information. Modified 2DHSQC experiments were performed to provide both one bond and two bond ${ }^{19} \mathrm{~F}_{-}{ }^{13} \mathrm{C}$ correlations. The combined use of these advanced 2D-NMR experiments made it possible to obtain unequivocal resonance assignments for the isomers present in hydrocarbon methyl-2,4,5-trimethyl-1,3-dioxolane-2-carboxylate, $\mathbf{3}$, and in fluorinated compounds, 4 and 5, derived from it. 


\section{CHAPTER II}

\section{EXPERIMENTAL}

\subsection{Synthesis}

Hydrocarbon precursor methyl-2,4,5-trimethyl-1,3-dioxolane-2-carboxylate, 3, was prepared by condensation of methyl pyruvate with 2,3-butanediol catalyzed by ptoluenesulfonic acid or strongly acidic ion-exchange resin Dowex 50WX8-100. Perfluoro-2,4,5-trimethyl-1,3-dioxolane-2-carboxylic acid, 4, was prepared by direct fluorination using a mixture of fluorine with nitrogen in a fluorinated solvent. Thermal decomposition of potassium perfluoro-2,4,5-trimethyl-1,3-dioxolane-2-carboxylate afforded the desired monomer perfluoro-2-methylene-4,5-dimethyl-1,3-dioxolane, 5 . These materials were provided by Prof. Y. Okamoto of Polytechnic Institute of New York University. Detailed descriptions of the preparations of the aforementioned intermediates and the final monomer are described elsewhere. ${ }^{31}$

\subsection{Materials}

Compounds 3 and 4 were dissolved in $\mathrm{CDCl}_{3}$, purchased from Cambridge Isotope Labs, Inc. For perfluorinated compound 4, one drop of hexafluorobenzene was added as the internal ${ }^{19} \mathrm{~F}$ signal shift reference. Hexafluorobenzene, purchased from Exfluor 
Research Corporation, was used as the solvent for perfluorinated monomer 5; a sealed 5 cm-height capillary tube containing benzene- $\mathrm{d}_{6}$ was inserted into the tube to provide a deuterium signal for lock. Methyl pyruvate was purchased from TCI and 2, 3-butanediol, p-toluenesulfonic acid, DOWEX 50WX-100 and all solvents were obtained from Aldrich.

\subsection{Instrumentation}

All spectra were collected on a Varian VNMRS $500 \mathrm{MHz}$ instrument with five broad band RF channels and a ${ }^{19} \mathrm{~F} /{ }^{13} \mathrm{C} /{ }^{1} \mathrm{H}$ triple resonance pulse field gradient (PFG) probe ${ }^{39}$ Both ${ }^{1} \mathrm{H}$ and ${ }^{19} \mathrm{~F}$ can be tuned on the same channel. The signals from the ${ }^{1} \mathrm{H}$ and

${ }^{19} \mathrm{~F}$ channels of the console are combined by a duplexer, which directs the mixed signals to a single RF port on the probe, which is doubly tuned to the ${ }^{1} \mathrm{H}$ and ${ }^{19} \mathrm{~F}$ frequencies. The ${ }^{1} \mathrm{H}$ or ${ }^{19} \mathrm{~F}$ signals from the probe were separated by a duplexer and the signal of interest (fluorine or proton signal) was directed to the receiver.

${ }^{1} \mathrm{H}$ and ${ }^{19} \mathrm{~F}$ 1D-NMR spectra. The chemical shifts of ${ }^{1} \mathrm{H},{ }^{13} \mathrm{C}$ and ${ }^{19} \mathrm{~F}$ were referenced relative to the $\mathrm{CHCl}_{3}$ in the solvent at $7.27 \mathrm{ppm}$, the $\mathrm{CDCl}_{3}$ solvent signal at $77.0 \mathrm{ppm}$, and the internal hexafluorobenzene at $-164.9 \mathrm{ppm}$, respectively. The ${ }^{1} \mathrm{H}$ NMR spectra were collected with $2.5 \mathrm{~s}$ acquisition time, $20 \mathrm{~s}$ relaxation delay, $3.0 \mathrm{kHz}$ spectral window, 16 transients, and $8.8 \mu \mathrm{s} 90^{\circ}$ pulse width. The data were zero-filled to $131 \mathrm{k}$, exponentially weighted with a line broadening of $0.5 \mathrm{~Hz}$, and Fourier transformed. 
The ${ }^{19} \mathrm{~F}$ 1D-NMR spectra were collected at $470 \mathrm{MHz}$ with $2 \mathrm{~s}$ acquisition time, 20 s relaxation delay, $37.8 \mathrm{kHz}$ window, 32 transients, and $3.2 \mu \mathrm{s} 30^{\circ}$ pulse width. The data were zero-filled to $256 \mathrm{k}$, exponentially weighted with a line broadening of $0.5 \mathrm{~Hz}$ and Fourier transformed.

${ }^{1} \mathrm{H}^{1} \mathrm{H}$ gdqCOSY $2 \mathrm{D}-\mathrm{NMR}$ experiment. The ${ }^{1} \mathrm{H}-{ }^{1} \mathrm{H}$ gdqCOSY experiment was performed with the standard Varian sequence. This was done with a $4.3 \mathrm{kHz}$ spectral width, $0.24 \mathrm{~s}$ acquisition time, $1 \mathrm{~s}$ relaxation delay and $7.8 \mu \mathrm{s} 90^{\circ}$ pulse width. Eight transients were averaged for each $2 \times 128$ increments using the States ${ }^{40}$ method of phase sensitive detection in $f_{1}$. Processing was done with shifted sinebell weighting functions in both dimensions and zero-filling to a $2048 \times 2048$ data matrix prior to Fourier transformation.

${ }^{1} \mathrm{H}_{-}{ }^{1} \mathrm{H}$ NOESY $2 \mathrm{D}-\mathrm{NMR}$ experiment. The ${ }^{1} \mathrm{H}-{ }^{1} \mathrm{H}$ NOESY experiment was performed with the standard Varian sequence. This was done with a $4.0 \mathrm{kHz}$ spectral width, $0.1 \mathrm{~s}$ acquisition time, $1.2 \mathrm{~s}$ relaxation delay, $2 \mathrm{~s}$ mixing time and $8.1 \mu \mathrm{s} 90^{\circ}$ pulse widths. Eight transients were averaged for each $2 \times 320$ increments in $f_{1}$ dimension using the States $^{40}$ method of phase sensitive detection. Processing was done with shifted sinebell weighting functions in both dimensions and zero-filling to a $2048 \times 2048$ data matrix prior to Fourier transformation.

${ }^{1} H_{-}{ }^{13} \mathrm{C}$ gHMBC $2 D-N M R$ spectrum. The gHMBC spectrum was obtained with $90^{\circ}$ pulse widths for ${ }^{1} \mathrm{H}$ and ${ }^{13} \mathrm{C}$ of 8.1 and $8.1 \mathrm{~ms}$, respectively, a $1 \mathrm{~s}$ relaxation delay, a $\mathrm{J}$ filter with delays of $3.5 \mathrm{~ms}$ (one-bond filter, based on ${ }^{1} \mathrm{~J}_{\mathrm{CH}}=146 \mathrm{~Hz}$ ) and a $0.50 \mathrm{~s}$ 
acquisition time; 8 transients were averaged for each of 2176 increments during $t_{1}$. The experiment was performed with a $\tau$ delay of $125 \mathrm{~ms}$ (optimized for ${ }^{\mathrm{n}} \mathrm{J}_{\mathrm{CH}}=4 \mathrm{~Hz}$ ). The evolution time was incremented to provide the equivalent of a $27.6 \mathrm{kHz}$ spectral width in the $f_{1}$ dimension, and a $3.0 \mathrm{kHz}$ spectral width was used in the $f_{2}$ dimension. Data were zero filled to a $4096 \times 4096$ matrix, and weighted with a sinebell function before Fourier transformation.

${ }^{19} \mathrm{~F}^{19} \mathrm{~F}$ gdqCOSY $2 D-N M R$ experiment. The ${ }^{19} \mathrm{~F}-{ }^{19} \mathrm{~F}$ gdqCOSY experiment was performed with the standard Varian sequence. This was done with a $15.8 \mathrm{kHz}$ spectral width, $0.128 \mathrm{~s}$ acquisition time, $1 \mathrm{~s}$ relaxation delay and $9.0 \mu \mathrm{s} 90^{\circ}$ pulse widths. Eight transients were averaged for each $2 \times 256$ increments using the States ${ }^{40}$ method of phase sensitive detection in $f_{1}$. Processing was done with shifted sinebell weighting functions in both dimensions and zero-filling to a $2048 \times 2048$ data matrix prior to Fourier transformation.

${ }^{19} \mathrm{~F}-{ }^{19} \mathrm{~F}$ Selective NOESY $2 D$-NMR experiments. The ${ }^{19} \mathrm{~F}-{ }^{19} \mathrm{~F}$ selective NOESY experiments were performed with the sequence implemented in our laboratory, ${ }^{24}$ using the following parameters: $0.129 \mathrm{~s}$ acquisition time, $1 \mathrm{~s}$ relaxation delay, $0.5 \mathrm{~s}$ mixing time; four transients were averaged for each $2 \times 256$ increments in the $f_{1}$ dimension using the States ${ }^{40}$ method of phase sensitive detection. The $90^{\circ}$ pulses used to excite the $f_{1}$ and $f_{2}$ windows were selective and had widths on order of 0.2-1.3 ms with an Eburp shape for excitation, and a Gaussian shape was used for an inversion pulse in the middle of the evolution period to cover the entire $f_{2}$ window. Processing was done with shifted sinebell 
weighting functions in both dimensions and zero-filling to a $2048 \times 2048$ data matrix prior to Fourier transformation.

${ }^{19} \mathrm{~F}\left\{{ }^{13} \mathrm{C}\right\}$ gHSQC $2 \mathrm{D}-\mathrm{NMR}$ experiments. ${ }^{19} \mathrm{~F}\left\{{ }^{13} \mathrm{C}\right\}$ gHSQC experiments were performed with a pulse sequence previously reported ${ }^{24}$ with ${ }^{13} \mathrm{C}$ decoupling during the acquisition period using WURST ${ }^{41}$ modulation $\left(\gamma_{\mathrm{BC}}=51.3 \mathrm{kHz}\right)$. Due to the large ${ }^{19} \mathrm{~F}$ spectral window, the gHSQC spectra of $\mathrm{CF}_{3}$ and $\mathrm{CF} / \mathrm{CF}_{2}$ regions were acquired in separate experiments. Experiments were performed based on $90^{\circ}$ pulse widths of 9.8 and $13.0 \mu$ s for ${ }^{19} \mathrm{~F}$ and ${ }^{13} \mathrm{C}$, respectively. The ${ }^{19} \mathrm{~F}$ dimension had a spectral width of $4.25 \mathrm{kHz}$ for the $\mathrm{CF}_{3}$ region $\left(6.61 \mathrm{kHz}\right.$ for $\mathrm{CF} / \mathrm{CF}_{2}$ region), and the ${ }^{13} \mathrm{C}$ dimension had a spectral width of $10.05 \mathrm{kHz}$ for the $\mathrm{CF}_{3}$ region $\left(13.82 \mathrm{kHz}\right.$ for $\mathrm{CF} / \mathrm{CF}_{2}$ region). Data were acquired with an acquisition time of $0.1 \mathrm{~s}, 1 \mathrm{~s}$ relaxation delay, and 8 transients were averaged for each $2 \times 512$ increments using the States ${ }^{40}$ method of phase sensitive detection in $f_{1}$. Delays were optimized depending on the couplings of interest. The delay $\Delta=1 / 4 \mathrm{~J}_{\mathrm{FC}}$ was set to $0.9 \mathrm{~ms}\left({ }^{1} \mathrm{~J}_{\mathrm{FC}}=270 \mathrm{~Hz}\right)$ for ${ }^{19} \mathrm{~F}-{ }^{13} \mathrm{C}$ correlations via one bond, and to $6.3 \mathrm{~ms}\left({ }^{2} \mathrm{~J}_{\mathrm{FC}}=40 \mathrm{~Hz}\right)$ for ${ }^{19} \mathrm{~F}_{-}{ }^{13} \mathrm{C}$ correlations via two bond couplings. The data were zero-filled to $2048 \times 2048$ and weighted with sinebell and shifted sinebell functions prior to Fourier transformation

${ }^{19} \mathrm{~F}^{19}{ }^{19} \mathrm{~F}$ Selective COSY $2 \mathrm{D}-\mathrm{NMR}$ experiments. The ${ }^{19} \mathrm{~F}-{ }^{19} \mathrm{~F}$ selective COSY experiments were performed with the sequence implemented in our laboratory ${ }^{24}$ using the following parameters: $0.12 \mathrm{~s}$ acquisition time, $1 \mathrm{~s}$ relaxation delay, and Eburp shaped pulses for both $f_{1}$ and $f_{2}$ dimension excitation. A Gaussian shaped pulse in the middle of the evolution period was used to invert the spins with resonances in the $f_{2}$ dimension. 
Four transients were averaged for each $2 \times 256$ increments in the $f_{1}$ dimension. The pulses used to excite $f_{1}$ and $f_{2}$ windows were selective and had widths on order of $0.2-1.3$ ms. Processing was done with shifted sinebell weighting functions in both dimensions and zero-filling to a $2048 \times 2048$ data matrix prior to Fourier transformation. 


\section{CHAPTER III}

\section{RESULTS AND DISCUSSION}

The substituted 1,3-dioxolane is characterized by two chiral centers in the 4- and 5-positions, and in the 2-position in the case of the isomers with $(4 \mathrm{R}, 5 \mathrm{~S})$ and $(4 \mathrm{~S}, 5 \mathrm{R})$ configurations, by a pseudochiral center. Four configurational isomers can be drawn assuming a planar conformation of the 1,3-dioxolane ring (Figure 11). ${ }^{42,43,44}$ The 4R,5Rand the 4S,5S-isomers have optical activity. The others represent meso forms with $(\mathrm{R}, \mathrm{S})$ and $(\mathrm{S}, \mathrm{R})$ configurations at the carbon atoms 4 and 5, and pseudo-chirality at position 2 . In this case, 2,2-disubstitution produces two different enantiomers, which are equivalent in an achiral environment.

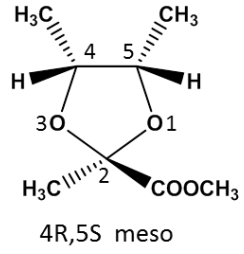

3a

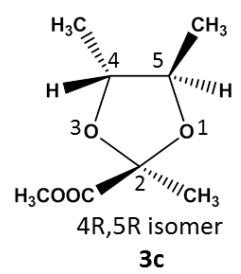

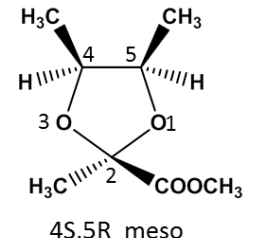

$3 \mathrm{~b}$

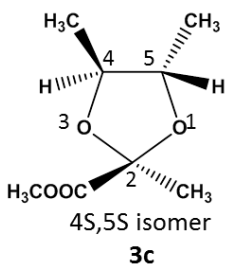

Figure 11. Configuration isomers of methyl-2,4,5-trimethyl-1,3-dioxolane-2-carboxylate. 
The two optically active isomers are dioxolane derivatives, which are derived from the two optically active R,R and S,S enantiomers of 2,3-butanediols. In this case, the carbon atom in the 2-position does not have pseudo-chirality. It should be pointed out that R,R and $\mathrm{S}, \mathrm{S}$ enantiomers of $\mathbf{3 c}$ (trans isomers), cannot be distinguished by NMR in an achiral medium, because the resonances of enantiotopic nuclei are isochronous. The $\mathrm{R}, \mathrm{S} / \mathrm{S}, \mathrm{R}$ isomers (meso forms), $\mathbf{3 a}$ and $\mathbf{3 b}$, are cis isomers containing substituted pseudo asymmetric carbons in the 2-positions, and can be distinguished because their resonances are anisochronous. NMR analysis permits resolution of resonance from two different isomers of the meso-form, 3a and $\mathbf{3 b}$. Two methyl groups in the 4- and 5-positions are in cis position relative to 1,3-dioxolane ring. In $\mathrm{R}, \mathrm{R}$ and $\mathrm{S}, \mathrm{S}$ isomers, $\mathbf{3 c}$, the 4-, and 5methyl substituents are trans to one another relative to 1,3-dioxolane ring.

3.1 Hydrocarbon precursor methyl-2,4,5-trimethyl-1,3-dioxolane-2-carboxylate (3)

The hydrocarbon precursor 3 was studied using ${ }^{1} \mathrm{H}-{ }^{1} \mathrm{H}$ selective COSY and NOESY 2D-NMR experiments to distinguish the resonances from trans and cis isomers. Then the gHMBC experiment was conducted to link the fragments. After assigning the resonances based on 2D-NMR spectra, quantitative 1D-NMR spectra were then used to confirm the assignments and to obtain the ratios of the isomers. 

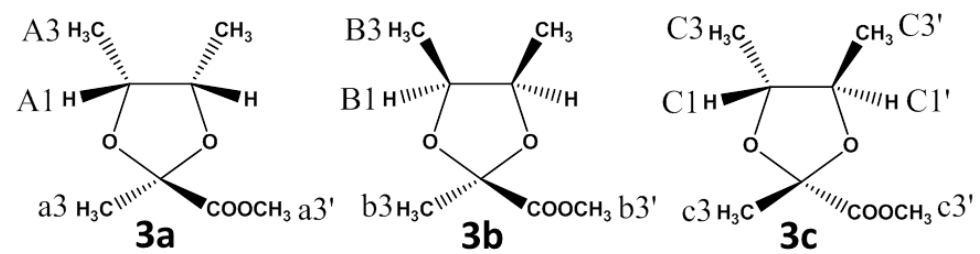

There are three possible isomers $(\mathbf{3 a}, \mathbf{3 b}, \mathbf{3 c})$ for hydrocarbon precursor methyl2,4,5-trimethyl-1,3-dioxolane-2-carboxylate (3). Isomer 3a has the 4,5 methyls (A3) cis to one another and to the 2-methyl substituent (a3). The $\mathrm{A} 3$ methyls and $\mathrm{CH}$ groups (labeled A1) each have the same chemical environments. A second methyl resonance arises from the methyl ester labeled a3'. Isomer $\mathbf{3 b}$, where the 4,5 methyls (B3) are cis to each another, and trans to the 2-methyl, produces three kinds of $\mathrm{CH}_{3}$ resonances (B3, b3 and $\mathrm{b}^{\prime}$ ') and one $\mathrm{CH}$ proton resonance (B1). Isomer $\mathbf{3 c}$, where the 4,5 methyls are trans to one another, should have four kinds of $\mathrm{CH}_{3} \mathrm{~s}\left(\mathrm{C} 3, \mathrm{C} 3\right.$ ', $\mathrm{c} 3$ and $\left.\mathrm{c} 3^{\prime}\right)$ and two kinds of CHs (C1 and $\left.\mathrm{Cl}^{\prime}\right)$. From integration of the ${ }^{1} \mathrm{H}$ 1D-NMR spectrum (Figure 12), it is only possible to identify resonances of different types of protons in this compound, i.e. $\mathrm{CHCH}_{3}, \mathrm{CCH}_{3}, \mathrm{COOCH}_{3}$ and $\mathrm{CH}$. Specific assignment cannot be made by simple inspection of the spectrum. The ${ }^{1} \mathrm{H}$ resonances of $\mathbf{C H}$ groups are more complicated (Figure 12d). 2D-NMR spectra provide valuable information about the unequivocal assignments of these resonances and atomic connectivity information. 

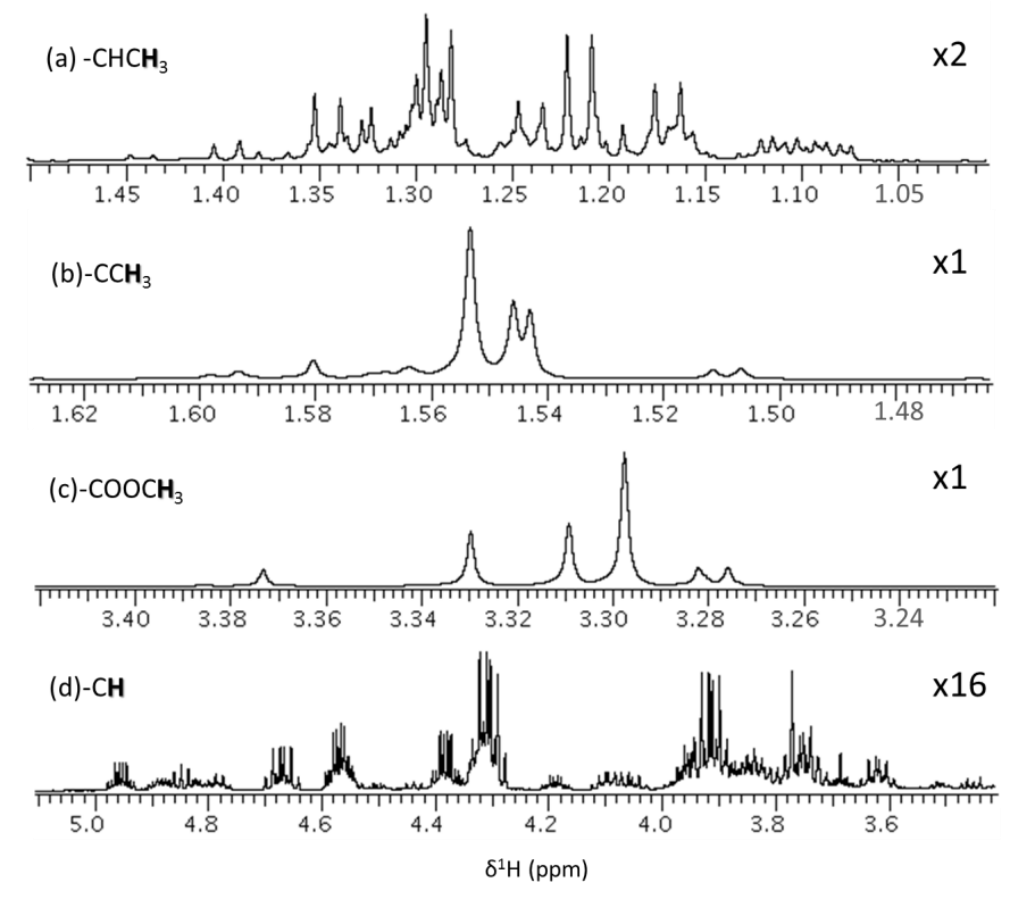

Figure 12. Selected regions from the $500 \mathrm{MHz}^{1} \mathrm{H}$ 1D-NMR spectrum of a mixture of isomers of 3: (a) $-\mathrm{CHCH}_{3}$ region, (b) $-\mathrm{CCH}_{3}$ region, (c) $-\mathrm{COOCH}_{3}$ region, and (d) $-\mathrm{CH}$ region.

Isomer 3c can be distinguished from the other two because; the two methine protons are nonequivalent. The resonances of $\mathrm{C} 1$ and $\mathrm{C} 1$ ' are correlated with each other in the ${ }^{1} \mathrm{H}-{ }^{1} \mathrm{H}$ dqCOSY spectrum (Figure 13). At the same time, the absence of a cross peak between these two resonances in the ${ }^{1} \mathrm{H}-{ }^{1} \mathrm{H}$ NOESY $2 \mathrm{D}-\mathrm{NMR}$ spectrum (Figure 14) is consistent with the trans arrangement of methine protons in isomer 3c. In isomer 3a, the methoxy group and the methine protons are on the same face of the ring. A NOESY cross peak is seen between the methine resonance at $3.92 \mathrm{ppm}$ and the methoxy proton resonance of the ester group in Figure 15. Therefore, the multiplet at $3.92 \mathrm{ppm}$ was assigned to A1 of isomer 3a. Because all of the methine proton resonances are correlated 
through three-bond coupling with the resonances of a quaternary carbon, the ${ }^{1} \mathrm{H}-{ }^{13} \mathrm{C}$ gHMBC spectrum can be used to find the methine resonance of isomer $\mathbf{3 b}$ (Figure 16).

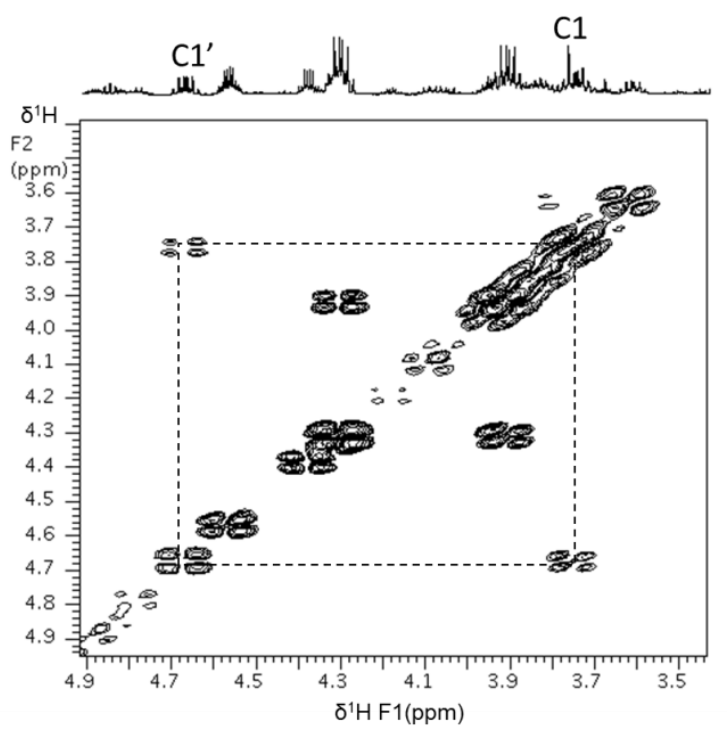

Figure 13. Selected region from the $500 \mathrm{MHz}{ }^{1} \mathrm{H}-{ }^{1} \mathrm{H}$ dqCOSY 2D-NMR spectrum from a mixture of $\mathbf{3 a}, \mathbf{3 b}, \mathbf{3} \mathbf{c}$.

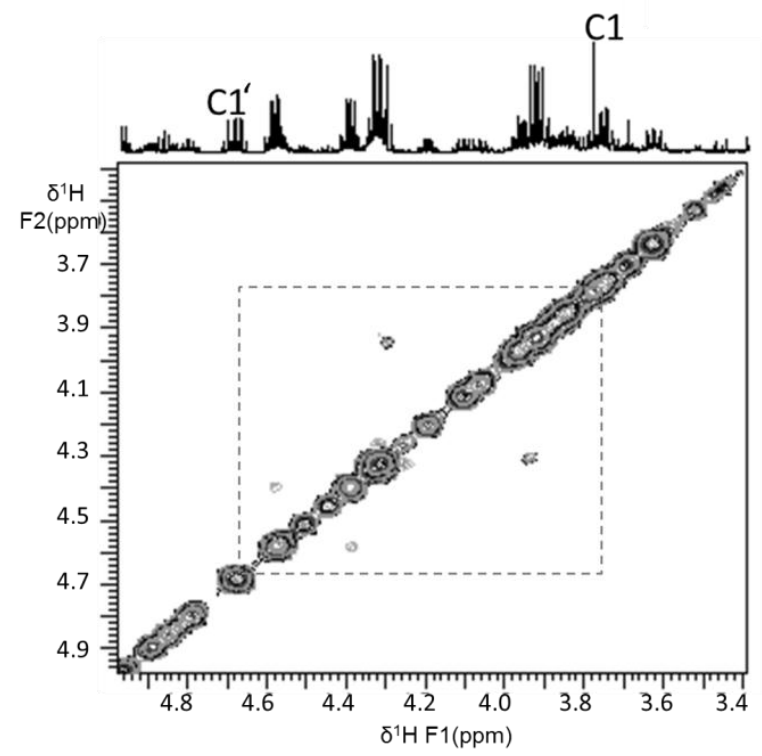

Figure 14. Selected region from the $500 \mathrm{MHz}{ }^{1} \mathrm{H}-{ }^{1} \mathrm{H}$ NOESY 2D-NMR spectrum from a mixture of isomers of 3 . 


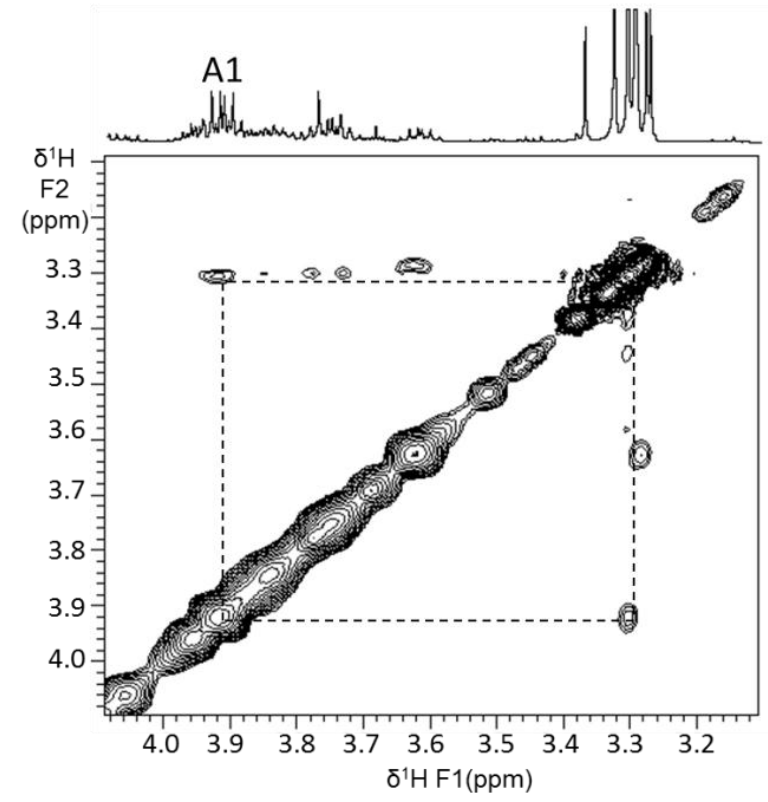

Figure 15. Selected region from the $500 \mathrm{MHz}{ }^{1} \mathrm{H}-{ }^{1} \mathrm{H}$ NOESY 2D-NMR spectrum of a mixture of $\mathbf{3 a}, \mathbf{3 b}, \mathbf{3 c}$.

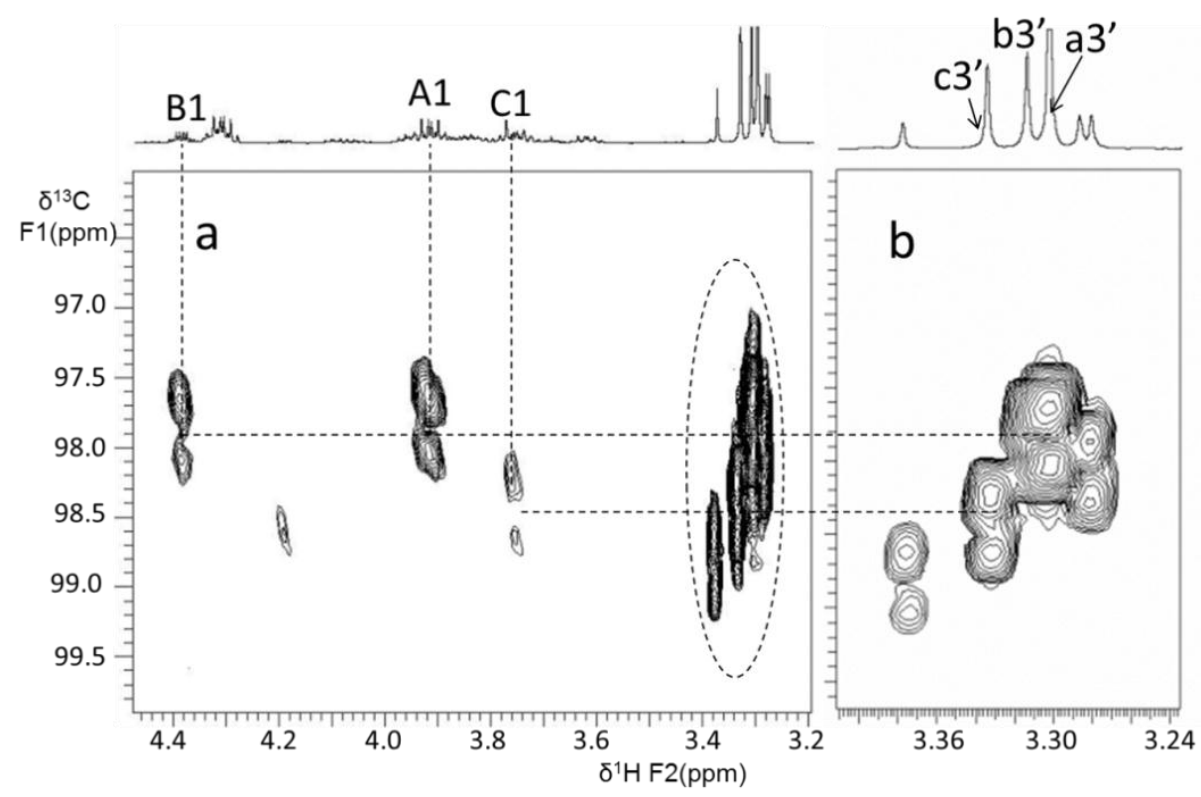

Figure 16. $500 \mathrm{MHz}{ }^{1} \mathrm{H}^{13} \mathrm{C}$ HMBC 2D-NMR spectrum of a mixture of 3a, 3b, 3c: (a) full region, (b) expansion of the region in the black circle in a. 
After identifying all the resonances in each isomer, it is also important to know the ratio of isomers. However, the complicated resonance patterns and signal overlap of the methine resonances prevent their use for accurate quantification of isomers. From the ${ }^{1} \mathrm{H}$ NMR spectrum (Figure 13), it can be seen that only the methyl protons of the ester groups are well resolved from each other. Therefore, it is necessary to assign the resonances between 3.29 and $3.33 \mathrm{ppm}$. The resonance of $\mathrm{Cl}^{\prime}$ is correlated with the resonance of the quaternary carbon at $98.4 \mathrm{ppm}$ (Figure 16). In addition, the resonance of this quaternary carbon is correlated with the methyl proton resonance at $3.33 \mathrm{ppm}$ (Figure 17). Therefore, this proton resonance is assigned to isomer $\mathbf{3 c}$. The limited resolution in the gHMBC spectrum prevents distinction between crosspeaks attributed to protons b3' and a3'. To accomplish this, the dqCOSY spectrum was used. In Figure 15, the resonance of A1 is correlated with a resonance at $3.30 \mathrm{ppm}$. Therefore, this proton resonance at 3.30 ppm is assigned to isomer 3a. In addition, the intensity of the signal from A1 is noticeably stronger than that of B1, suggesting that there is more of isomer $\mathbf{3 a}$ than $\mathbf{3 b}$ (Figure 16). This further confirms that the stronger peak at $3.30 \mathrm{ppm}$ should be attributed to isomer $\mathbf{3 a}$.

Because the methyl proton resonances of the ester groups are well resolved from each other, they were used to calculate the ratio of the three isomers. Based on the quantitative ${ }^{1} \mathrm{H}$ NMR results, the percentages of isomer $\mathbf{3 a}, \mathbf{3 b}$ and $\mathbf{3} \mathbf{c}$ are $52.2 \%, 26.0 \%$ and $21.8 \%$, respectively (Figure 18 ). 


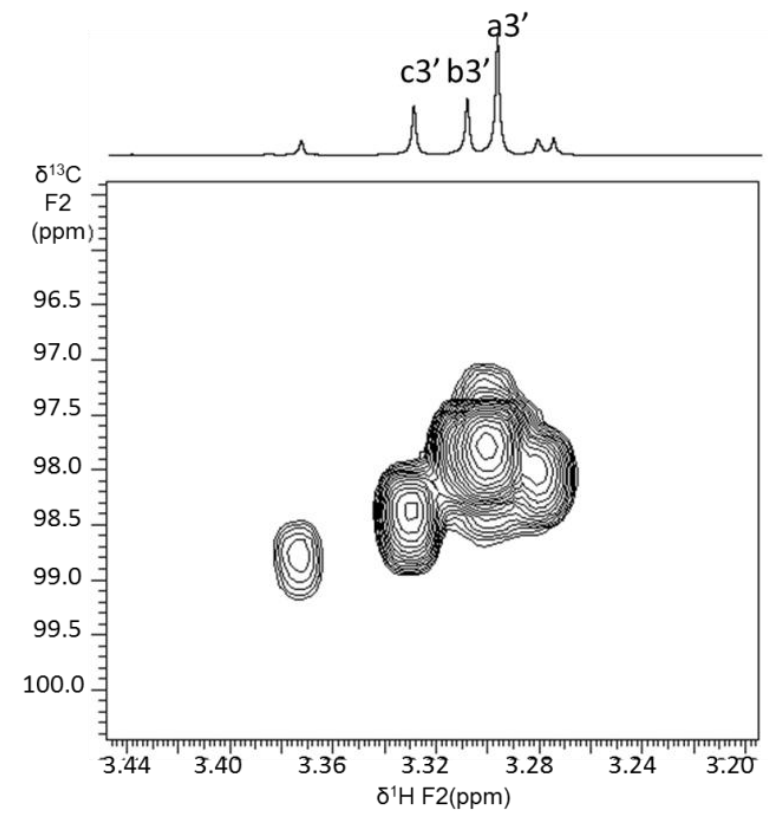

Figure 17. Selected region from the $500 \mathrm{MHz}{ }^{1} \mathrm{H}_{-}{ }^{13} \mathrm{C}$ gHMBC 2D-NMR spectrum of a mixture of isomers of $\mathbf{3}$ showing correlations between the methyl proton resonances and the ketal carbon resonances.

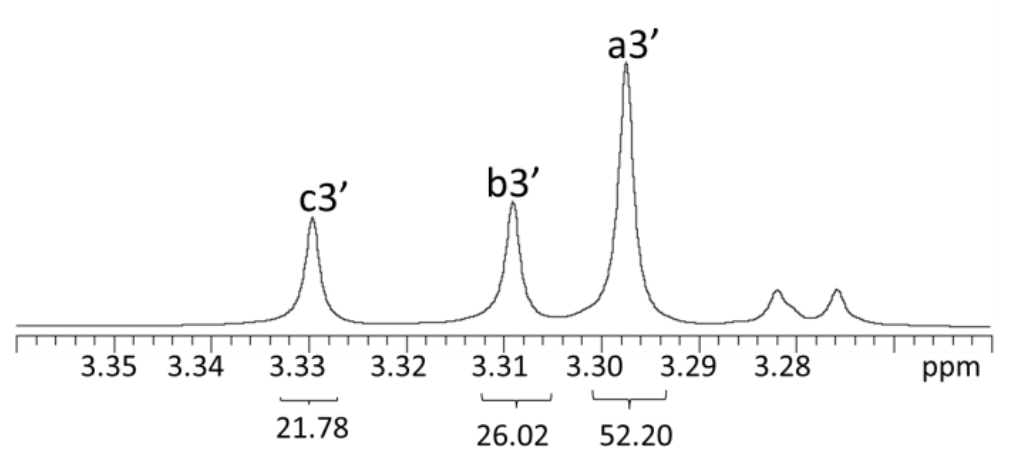

Figure 18. Selected region from the quantitative $500 \mathrm{MHz}{ }^{1} \mathrm{H}$ 1D-NMR spectrum from a mixture of $\mathbf{3 a}, \mathbf{3 b}$ and $\mathbf{3 c}$. 
Table 1. Summary of chemical shift assignments for 3 .

\begin{tabular}{|c|c|c|c|c|}
\hline & $\mathrm{CH}_{\underline{\mathrm{CH}}_{3}}$ & $\mathrm{CCH}_{3}$ & $\mathrm{CHCH}_{3}$ & $\mathrm{COOCH} \underline{H}_{3}$ \\
\hline $\begin{array}{r}{ }^{1} \mathrm{H} \text { chemical shifts } \\
\text { (ppm) }\end{array}$ & $\begin{array}{l}\text { A3: } 1.116(d) ; \\
\text { B3: } 1.170(d) ; \\
\text { C3: } 1.240(d) \text {; } \\
\text { C3': } 1.294(d)\end{array}$ & $\begin{array}{r}\text { a3: } 1.553(\mathrm{~s}) \\
\mathrm{b} 3+\mathrm{c} 3: 1.546(\mathrm{~s}) \\
\text { and } 1.543(\mathrm{~s})\end{array}$ & $\begin{array}{l}\mathrm{A} 1: 3.920 \\
\mathrm{~B} 1: 4.380 \\
\mathrm{C} 1: 4.670 \\
\mathrm{C} 11^{\prime}: 3.760\end{array}$ & $\begin{array}{l}\text { a3': } 3.297(\mathrm{~s}) \text {; } \\
\text { b3': } 3.309(\mathrm{~s}) ; \\
\text { c3': } 3.330(\mathrm{~s}) \text {. }\end{array}$ \\
\hline $\begin{array}{r}{ }^{13} \mathrm{C} \text { chemical } \\
\text { shifts } \\
(\mathrm{ppm})\end{array}$ & & $\begin{array}{r}\text { a3: } 20.77(\mathrm{~s}) \\
\mathrm{b} 3+\mathrm{c} 3: 20.67(\mathrm{~s}) \\
\text { and } 20.90(\mathrm{~s})\end{array}$ & $\begin{array}{l}\text { A1:68.13; } \\
\text { B1:66.21; } \\
\text { C1':77.78. }\end{array}$ & $\begin{array}{r}\text { a3': } 49.16(\mathrm{~s}) ; \\
\mathrm{b} 3^{\prime}+\mathrm{c} 3^{\prime}: \\
48.74 / \\
\text { and } 48.69 .\end{array}$ \\
\hline
\end{tabular}

a) The fluorine chemical shifts are based on the ${ }^{19} \mathrm{~F}$ 1D-NMR spectrum. The carbon chemical shifts are based on one bond and two bond HSQC 2D-NMR experiments. b) The assigned carbon chemical shifts of $\mathrm{COOH}$ is absent due to the absence of one and two bond fluorine correlations.

The mixture of stereoisomers of methyl-2,4,5-trimethyl-1,3-dioxolane-2carboxylate was analyzed by GC-MS as well. The GC-MS trace contains essentially three peaks. Two of them are meso isomers and the third peak represents R,R and S,S enantiomers, which cannot be separated on an achiral column. These three peaks show the same mass spectra at different elution times.

\subsection{Perfluoro-2,4,5-trimethyl-1,3-dioxolane-2-carboxylic acid (4)}

The structure of monomer precursor $\mathbf{4}$ is similar to that of $\mathbf{3}$, thus a sample $\mathbf{4}$ also has three isomers. The nomenclature used to describe the atoms in this structure is the same as that used for precursor 3. After fluorination, all the protons, except the 
exchangeable carboxylic acid proton, are replaced with fluorine atoms. ${ }^{19} \mathrm{~F}$ 1D-NMR (Figure 19) is used to identify and quantitate these isomers.
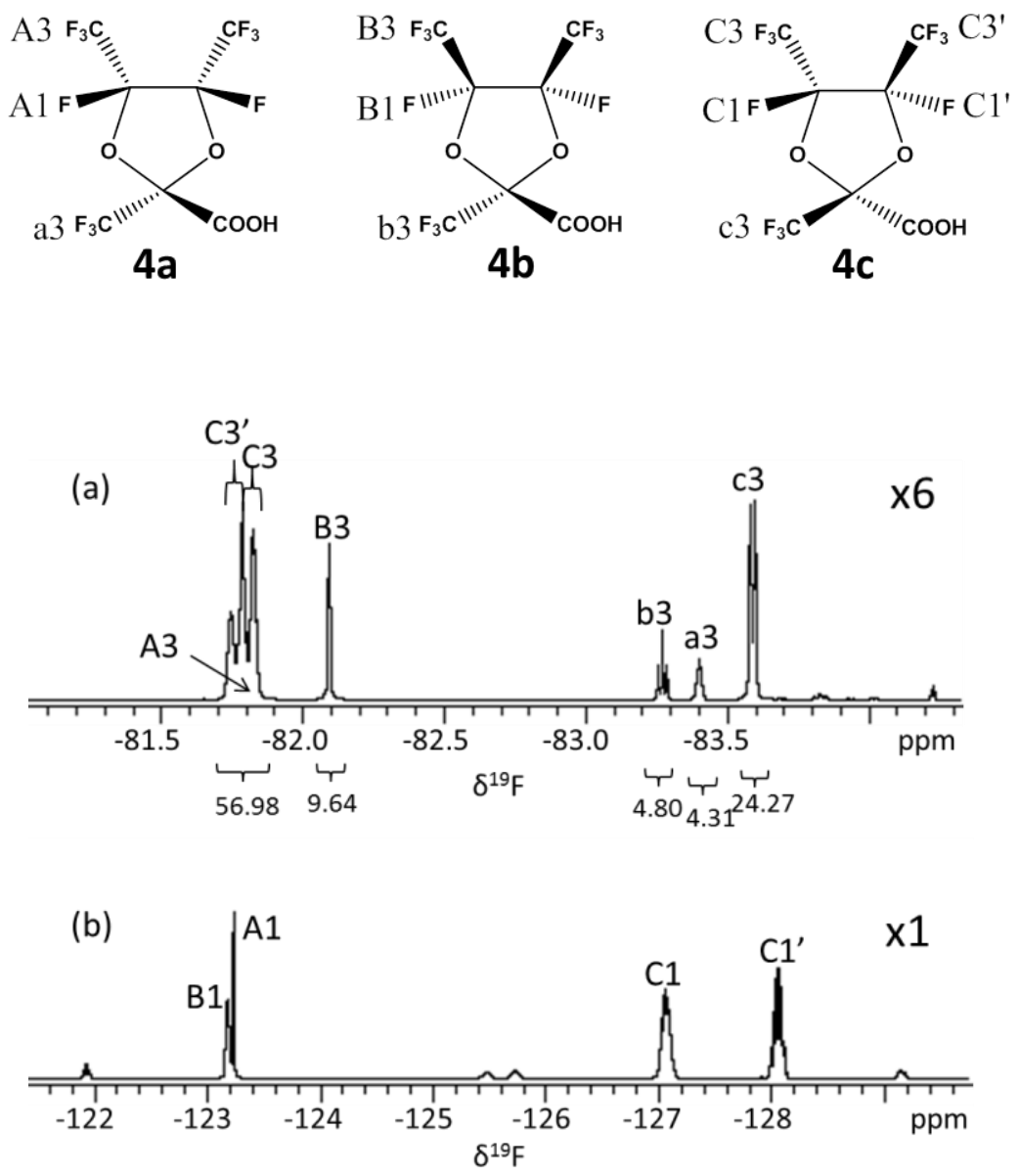

Figure 19. Selected regions from the $470 \mathrm{MHz}{ }^{19} \mathrm{~F} 1 \mathrm{D}-\mathrm{NMR}$ spectrum of perfluoro-2,4,5trimethyl-1,3-dioxolane-2-carboxylic acid (4) showing: (a) the $\mathrm{CF}_{3}$ region, and (b) the $\mathrm{CF}$ region.

\subsubsection{Identification of isomer $\mathbf{4 c}$}

Two resonances are expected for the $-\mathrm{CF}$ fluorine atoms in isomer 4c. From the gdqCOSY NMR spectrum (Figure 20), it can be seen that the resonances of $\mathrm{C} 1$ and $\mathrm{Cl}$ ' 
are correlated with each other. In the ${ }^{19} \mathrm{~F}-{ }^{19} \mathrm{~F}$ NOESY spectrum, there is no correlation between the resonances of $\mathrm{C} 1$ and $\mathrm{C} 1$ ' (Figure 21). This is expected due to their trans relationship. This evidence indicates that there are two nonequivalent fluorine atoms trans to one another in isomer $4 \mathbf{c}$. To further confirm this, the integrals for $\mathrm{C} 1$ and $\mathrm{Cl}$ ' match each other in the quantitative ${ }^{19} \mathrm{~F}$ NMR spectrum.

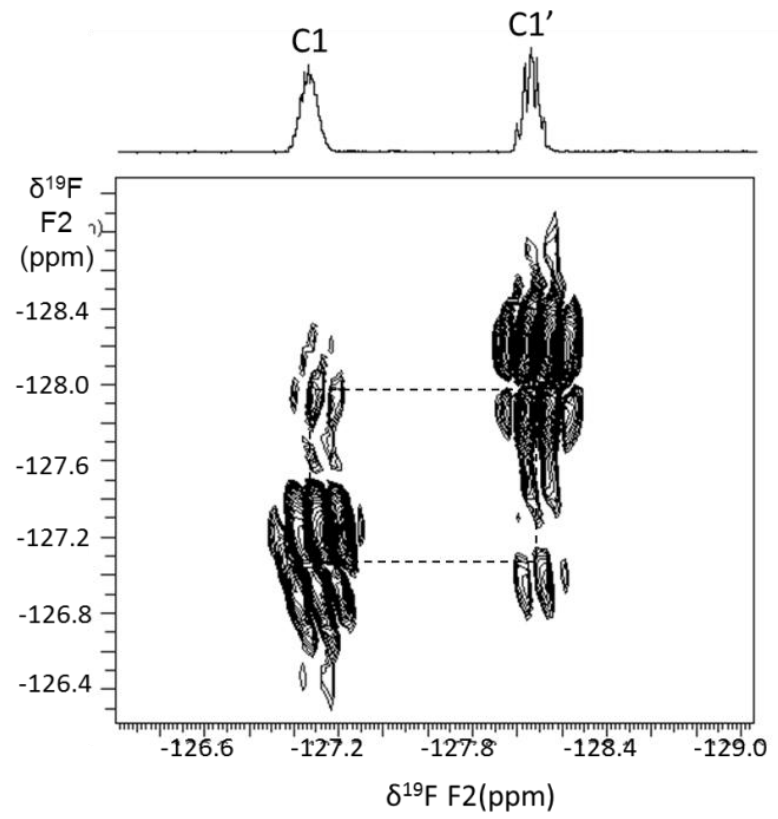

Figure 20. Selected region from the $470 \mathrm{MHz}{ }^{19} \mathrm{~F}^{19} \mathrm{~F}^{2} \mathrm{gdqCOSY}$ 2D-NMR spectrum from a mixture of isomers of perfluoro-2,4,5-trimethyl-1,3-dioxolane-2-carboxylic acid (4). 


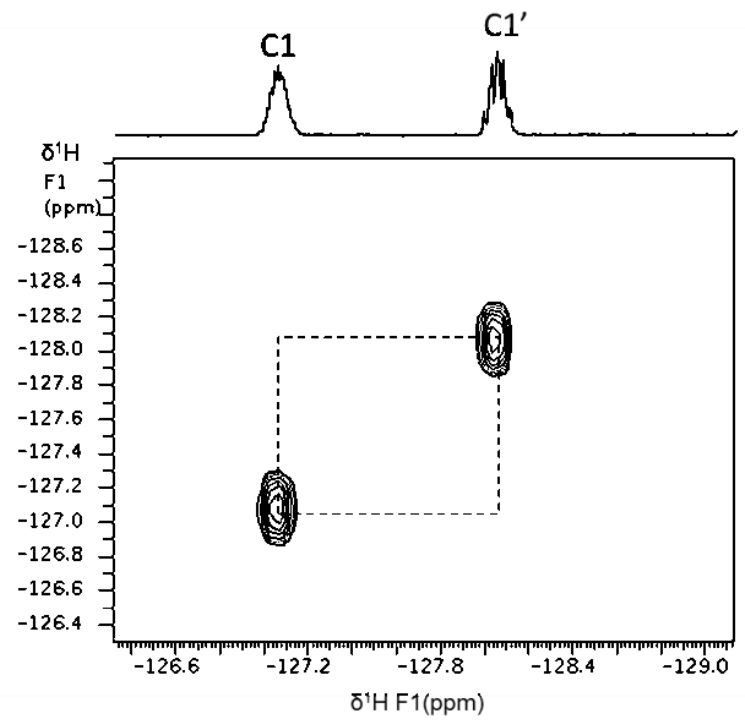

Figure 21. Selected region from the $470 \mathrm{MHz}{ }^{19} \mathrm{~F}-{ }^{19} \mathrm{~F}$ NOESY $2 \mathrm{D}-\mathrm{NMR}$ spectrum of isomers in 4.

Because the full ${ }^{19} \mathrm{~F}$ spectral window is very large $(37.8 \mathrm{kHz})$, it is difficult to excite the whole window to observe the weak ${ }^{19} \mathrm{~F}-{ }^{19} \mathrm{~F}$ interactions between $\mathrm{CF}$ and $\mathrm{CF}_{3}$ groups by the normal NOESY experiment. Here, a selective version of the NOESY experiment was used to excite specific regions of the ${ }^{19} \mathrm{~F}$ spectrum containing the resonances of interest. The region containing CF fluorine resonances (-20.98 to -128.81 ppm) was set as the indirectly detected spectral window $\left(f_{1}\right)$; and the region of $\mathrm{CF}_{3}$ fluorine resonances was set as the directly detected spectral window $\left(f_{2}\right)$. NOESY type NMR experiments are based on dipole-dipole interactions, which indicate the correlations in the spectra are from through space interactions, which diminish as the inverse sixth power of the internuclear distance. In the selective NOESY spectrum (Figure 22), it can be seen that only the resonance of $\mathrm{C} 1$ is correlated with the resonances of two $-\mathrm{CF}_{3}$ fluorine atoms ( $\mathrm{C} 3$ ' and $\mathrm{c} 3)$, therefore the fluorine atoms $\mathrm{C} 1, \mathrm{C} 3$ ' and $\mathrm{c} 3$ are on the same 
isomer $4 \mathbf{c}$ and are cis to each other. As for the resonance of $\mathrm{Cl}^{\prime}$, it is only correlated with $\mathrm{C} 3$ 's $-\mathrm{CF}_{3}$ fluorine resonance in isomer $4 \mathbf{c}$. There is no correlation between the resonances of $\mathrm{Cl}^{\prime}$ and $\mathrm{c} 3$ as they are on opposite sides of the ring.

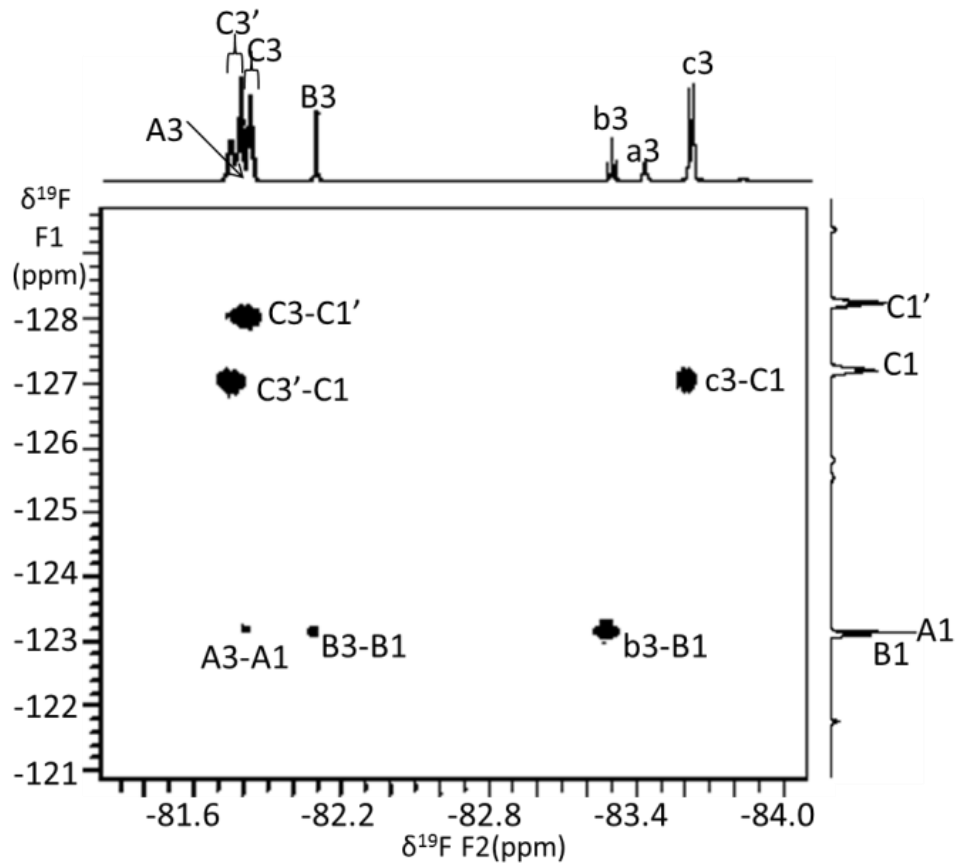

Figure 22. $470 \mathrm{MHz}{ }^{19} \mathrm{~F}^{19}{ }^{19}$ selective NOESY NMR spectrum of perfluoro-2,4,5trimethyl-1,3-dioxolane-2-carboxylic acid.

\subsubsection{Identification of isomer $\mathbf{4 b}$}

Isomer $\mathbf{4 b}$ can be distinguished from isomer $\mathbf{4 a}$ since the $-\mathrm{CF}_{3}$ group (b3) attached to the quaternary carbon and the B1 fluorines are on the same side of the ring. The correlation between B1 (-123.01 ppm) and b3 (-83.30 ppm) in the selective NOESY spectrum proves that they are on the same side of the ring, and these resonances are 
therefore assigned to isomer $\mathbf{4 b}$. The resonance at $-82.09 \mathrm{ppm}$ is assigned to $\mathrm{B} 3$ due to the correlation between the resonances of B3 and B1 in the selective NOESY spectrum.

\subsubsection{Identification of isomer $4 \mathbf{a}$}

The resonance of $\mathrm{A} 3$ in isomer $\mathbf{4 a}$, is buried under resonance $\mathrm{C} 3 / \mathrm{C} 3$ '. It was resolved in the selective NOESY spectrum, the only correlation in isomer 4a is between the resonance of $\mathrm{A} 1$ and that of $\mathrm{A} 3$. Therefore, the singlet at $-123.02 \mathrm{ppm}$ is attributed to A1. The absence of a correlation between A1 and the a3 is consistent with a structure where they are on opposite sides of the ring in isomer $4 \mathbf{a}$.

\subsubsection{Quantitative ${ }^{19} \mathrm{~F}$ NMR results}

From the $-\mathrm{CF}_{3}$ region (Figure 19), it can be seen that the $-\mathrm{CF}_{3}$ groups on the quaternary carbon contribute to the resonances between -83.2 and $-83.7 \mathrm{ppm}$. The $-\mathrm{CF}_{3}$ groups on the tertiary carbon produce the resonances between -81.6 and $-82.2 \mathrm{ppm}$. The ratio of the two types of fluorine atoms is $1: 2$ as expected. In addition, B3 is better resolved, the ratio of $\mathrm{b} 3$ to $\mathrm{B} 3$ also matches the predicted ratio of 1:2. This quantitative information further confirms the assignments from the 2D-NMR experiments described above. The ratio of the three isomers can be calculated from the quantitative ${ }^{19} \mathrm{~F}$ NMR spectrum. The ratio of isomer $\mathbf{4 a}, \mathbf{4 b}$ and $\mathbf{4 c}$ is 1.00:1.11:5.63. 
Table 2. Summary of chemical shift assignments for 4 .

\begin{tabular}{|c|c|c|c|c|}
\hline & $\mathrm{CF}_{\mathbf{C F}}{ }_{3}$ & $\mathrm{C}_{\mathbf{C F}}{ }_{3}$ & $\underline{\mathrm{CFCF}_{3}}$ & $\underline{\mathbf{C C O O H}}$ \\
\hline $\begin{array}{r}{ }^{19} \mathrm{~F} \text { chemical shifts } \\
(\mathrm{ppm})\end{array}$ & $\begin{array}{r}\text { A3: }-81.78 ; \\
\text { B3: }-82.09(\mathrm{~d}) \text {; } \\
\text { C3: }-81.80(\mathrm{~d}) \text {; } \\
\text { C3': }-81.76(\mathrm{~d}) \text {. }\end{array}$ & $\begin{array}{l}\text { a3: }-83.43(\mathrm{~s}) \\
\text { b3: }-83.28(\mathrm{t}) \\
\text { c3: }-83.61(\mathrm{~d})\end{array}$ & $\begin{array}{r}\text { A1: }-123.21(\mathrm{~s}) ; \\
\text { B1: }-123.17 \\
\text { (quartet); } \\
\text { C1: }-127.06(\mathrm{~m}) ; \\
\text { C1': }-128.05 \\
\text { (quintet). }\end{array}$ & \\
\hline $\begin{array}{r}{ }^{13} \mathrm{C} \text { chemical } \\
\text { shifts } \\
(\mathrm{ppm})\end{array}$ & $\begin{array}{l}\text { A3: 117.82; } \\
\text { B3: 117.93; } \\
\text { C3: 117.75; } \\
\text { C3':117.61. }\end{array}$ & $\begin{array}{l}\text { a3: } 118.56 \\
\text { b3: } 117.93 \\
\text { c3: } 118.61\end{array}$ & $\begin{array}{r}\text { A1: } 110.15 \\
\text { B1: } 109.83 \\
\text { C1: } 110.54 \\
\text { C1': } 110.58 \\
\end{array}$ & $\begin{array}{l}\text { a3: } 103.52 \\
\text { b3: } 103.50 \\
\text { c3: } 105.30\end{array}$ \\
\hline
\end{tabular}

a) The fluorine chemical shifts are based on the ${ }^{19} \mathrm{~F}$ 1D-NMR spectrum. The carbon chemical shifts are based on one bond and two bond HSQC 2D-NMR experiments.

b) The assigned carbon chemical shifts of $\mathrm{COOH}$ is absent due to the absence of one and two bond fluorine correlations.

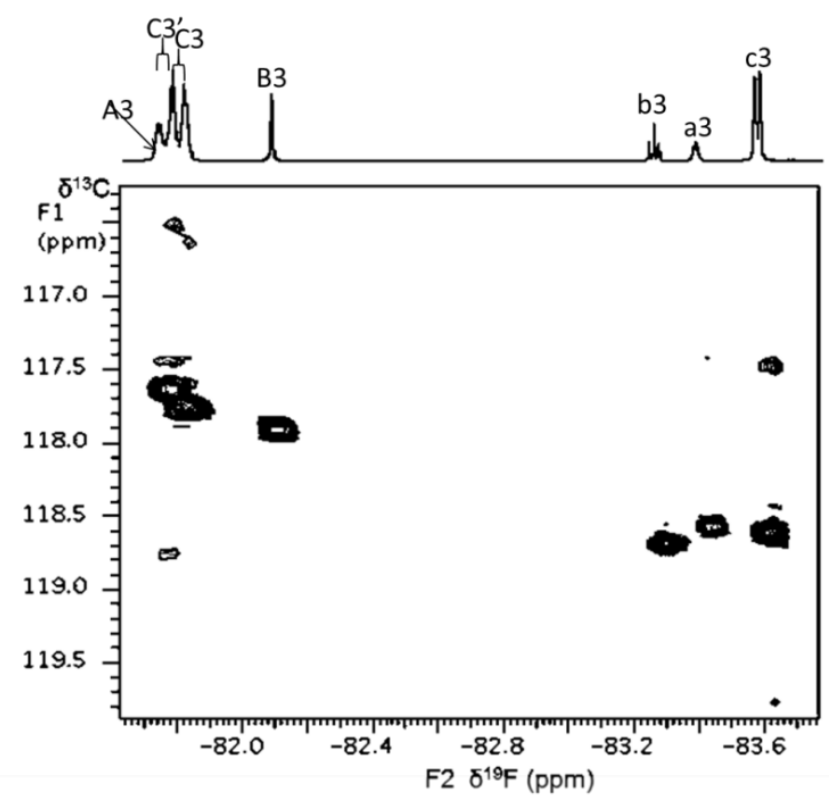

Figure 23. $470 \mathrm{MHz}{ }^{19} \mathrm{~F}_{-}{ }^{13} \mathrm{C}$ one bond HSQC $2 \mathrm{D}-\mathrm{NMR}$ spectrum of isomers in $4\left(\mathrm{CF}_{3}\right.$ region). 


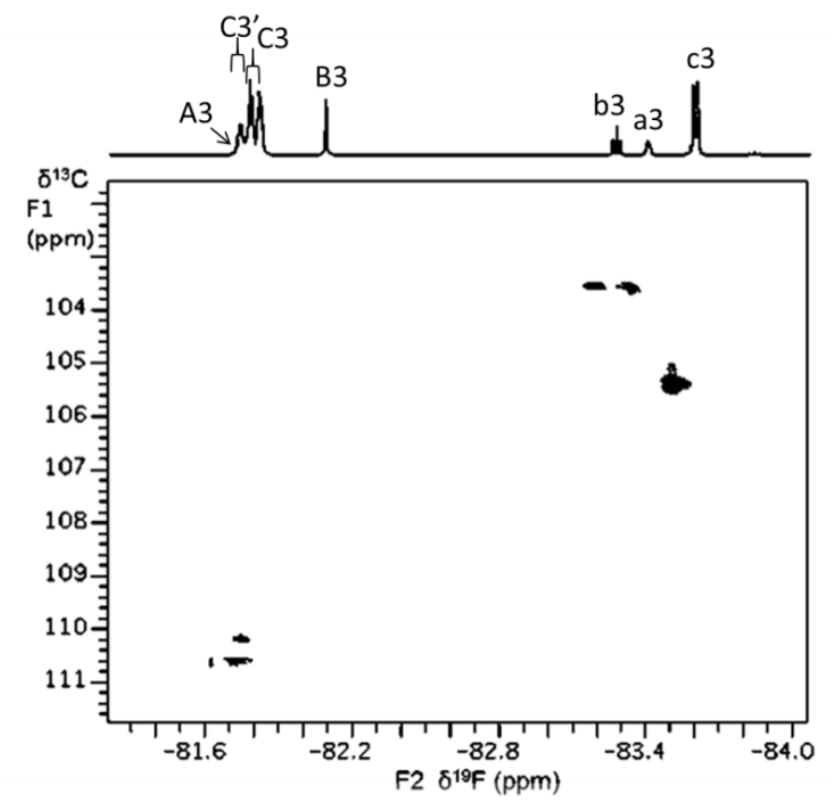

Figure 24. $470 \mathrm{MHz}^{19} \mathrm{~F}-{ }^{13} \mathrm{C}$ two bond 2D-NMR HSQC spectrum of isomers in $\mathbf{4}\left(\mathrm{CF}_{3}\right.$ region).

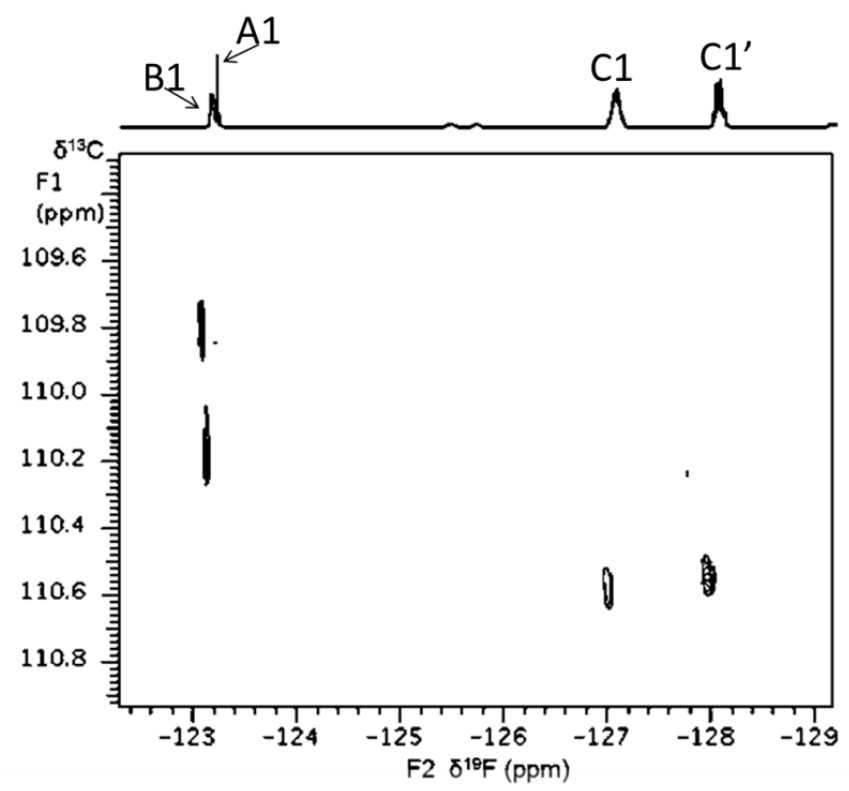

Figure $25.470 \mathrm{MHz}{ }^{19} \mathrm{~F}^{13} \mathrm{C}$ two bond 2D-NMR HSQC spectrum of isomers in 4 (CF region). 
It has been recognized for some time that organic fluorination reactions with elemental fluorine exhibit the general characteristics of free radical processes. ${ }^{45,46,47}$ Fluorination at the $\mathrm{C}-4$ or $\mathrm{C}-5$ position of the 1,3-dioxolane ring leaves the chiral center (C-4 or C5) unchanged, but the free radical generated by hydrogen abstraction is planar and has two different faces with different steric hindrance. For this reason, the two products will be formed in unequal yields. The formation R,R and S,S isomers is more probable. Less steric hindrance of bulky trifluoromethyl substituents in trans position at C-4 and C-5 positions in the 1,3-dioxolane ring is the driving force. The contents of cis and trans isomers in methyl-2,4,5-trimethyl-1,3-dioxolane-2-carboxylate (3) and in perfluoro-2,4,5-trimethyl-1,3-dioxolane-2-carboxylic acid (4) are reversed. The configurational composition of the resulting perfluorinated acid (4) supports the proposed mechanism of fluorination using elemental fluorine where fluorine replaces the hydrogens by stepwise radical reactions.

\subsection{Perfluoro-2-methylene-4,5-dimethyl-1,3-dioxolane (5)}

Monomer 5 has two isomers, depending on the trans or cis orientation of the two $\mathrm{CF}_{3}$ groups. The atom labels used for $\mathbf{5}$ are a little different from those used for $\mathbf{3}$ and $\mathbf{4}$. The alkene $\mathrm{CF}_{2}$ fluorines are labeled as $\mathrm{A} 2$ in cis isomer and $\mathrm{B} 2$ in trans isomer. Figure 26 shows the $470 \mathrm{MHz}{ }^{19} \mathrm{~F}$ 1D-NMR spectrum for monomer 5. From the previous analysis, it is known that the resonances of $\mathrm{CF}_{3}$ fluorines are shifted to lower field relative to those of $\mathrm{CF}$ fluorines. The first step in characterizing monomer $\mathbf{5}$ is to find the resonance positions of the alkene $\mathrm{CF}_{2}$ fluorines. Then, based on the ${ }^{19} \mathrm{~F}-{ }^{19} \mathrm{~F}$ correlations in 
the selective COSY spectrum, the two sets of resonances from each monomer can be identified. These resonance assignments were confirmed by the ${ }^{1} \mathrm{~J}_{\mathrm{FC}}$ and ${ }^{2} \mathrm{~J}_{\mathrm{FC}}$ gHSQC $2 \mathrm{D}-$ NMR experiments. Finally, the quantitative ${ }^{19} \mathrm{~F}$ 1D-NMR spectrum was used to confirm the resonance assignments and to calculate the ratio of the two isomers.
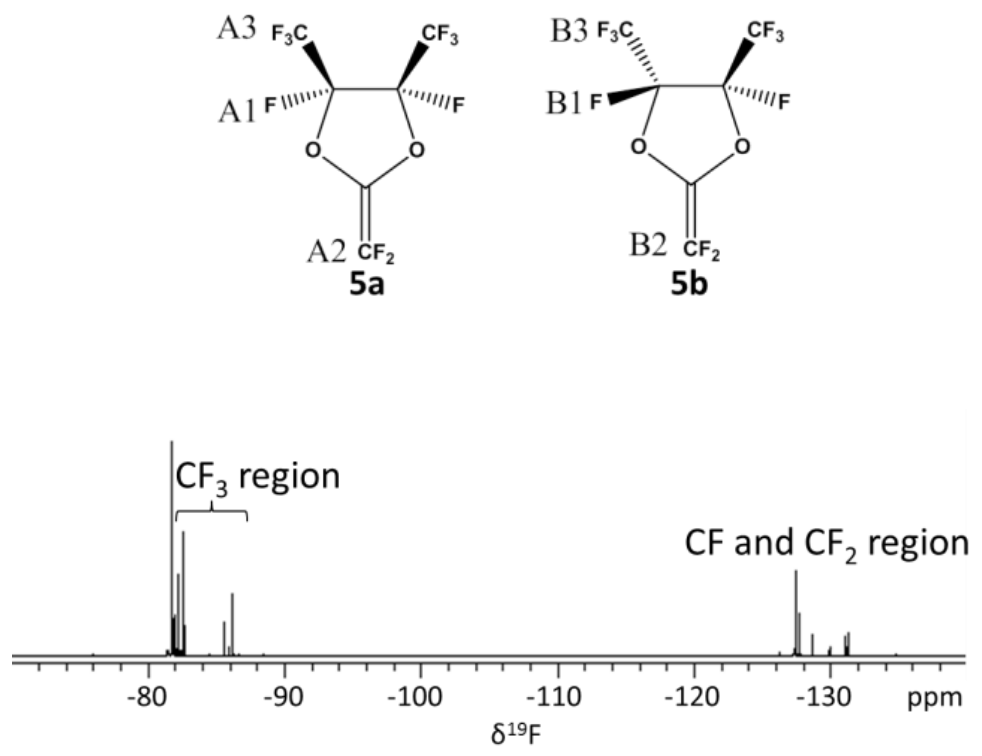

Figure 26. $470 \mathrm{MHz}{ }^{19} \mathrm{~F}$ 1D-NMR spectrum of isomers of 5 .

A modified version of the ${ }^{19} \mathrm{~F}\left\{{ }^{13} \mathrm{C}\right\}$ gHSQC experiment was applied successfully in the study of these fluorine-containing molecules. In the modified gHSQC sequence, ${ }^{24}$ a $\mathrm{TANGO}^{48}$ (testing for adjacent nuclei with a gyration operator) pulse sequence element was inserted at the beginning of this sequence to selectively excite fluorines bonded to ${ }^{13} \mathrm{C}$ or ${ }^{12} \mathrm{C}$. Due to the large difference between ${ }^{1} \mathrm{~J}_{\mathrm{FC}},{ }^{2} \mathrm{~J}_{\mathrm{FC}}$ and ${ }^{3} \mathrm{~J}_{\mathrm{FC}}$, this sequence can be used to detect exclusively one-bond or two-bond ${ }^{19} \mathrm{~F}-{ }^{13} \mathrm{C}$ correlations by optimizing the delays based on ${ }^{1} \mathrm{~J}_{\mathrm{FC}}$ or ${ }^{2} \mathrm{~J}_{\mathrm{FC}}$. Compared to the standard gHMBC experiment, the gHSQC 
experiment eliminates problems from complicated splitting patterns due to ${ }^{19} \mathrm{~F}-{ }^{19} \mathrm{~F}$ homonuclear couplings in the $f_{1}$ dimension, which are caused by the evolution of multiple-quantum coherence during the $t_{1}$ evolution period. The ${ }^{2} \mathrm{~J}_{\mathrm{FC}}$ gHSQC spectrum is simplified due to the absence of such multiple-quantum coherence evolution during $t_{1}$. In addition, the use of decoupling during acquisition period can further simplify the spectrum. All of these factors contribute to the enhanced resolution and sensitivity in ${ }^{2} \mathrm{~J}_{\mathrm{FC}}$ gHSQC spectrum when compared to the HMBC spectrum.

Figure 27 shows selected peak-containing regions from the ${ }^{1} \mathrm{~J}_{\mathrm{FC}}$ and ${ }^{2} \mathrm{~J}_{\mathrm{FC}}{ }^{19} \mathrm{~F}\left\{{ }^{13} \mathrm{C}\right\}$ gHSQC spectra. Because the chemical shift range in the ${ }^{19} \mathrm{~F}$ spectrum is very large, and there is no useful information between $-90 \mathrm{ppm}$ and $-125 \mathrm{ppm}$, two gHSQC NMR experiments were carried out to excite the $\mathrm{CF} / \mathrm{CF}_{2}$ and $\mathrm{CF}_{3}$ regions, separately. In this way, digital resolution is significantly improved by focusing on the regions containing useful structural information. The fluorine resonances from $=\mathrm{CF}_{2}$ groups can easily be found since they are the only fluorine resonances correlated with olefinic carbon resonances in the ${ }^{1} \mathrm{~J}_{\mathrm{FC}}-\mathrm{HSQC}$ spectrum. The ${ }^{13} \mathrm{C}$ chemical shifts of the two olefinic carbons are about 142.4 and $142.5 \mathrm{ppm}$. Therefore, the ${ }^{19} \mathrm{~F}$ resonances at -127.76 and $127.50 \mathrm{ppm}$ are assigned to $\mathrm{A} 2$ and $\mathrm{B} 2$, respectively, attributed to the $=\mathrm{CF}_{2}$ groups. Their corresponding carbon chemical shifts can be observed in the ${ }^{1} \mathrm{~J}_{\mathrm{FC}}$ gHSQC spectrum. The fluorine chemical shifts in ${ }^{1} \mathrm{~J}_{\mathrm{FC}}$ gHSQC spectrum are shifted about $0.1 \mathrm{ppm}$ to higher field compared to the ${ }^{19} \mathrm{~F}$ 1D-NMR chemical shifts due to the ${ }^{13} \mathrm{C}$ isotope effect. ${ }^{49}$ 


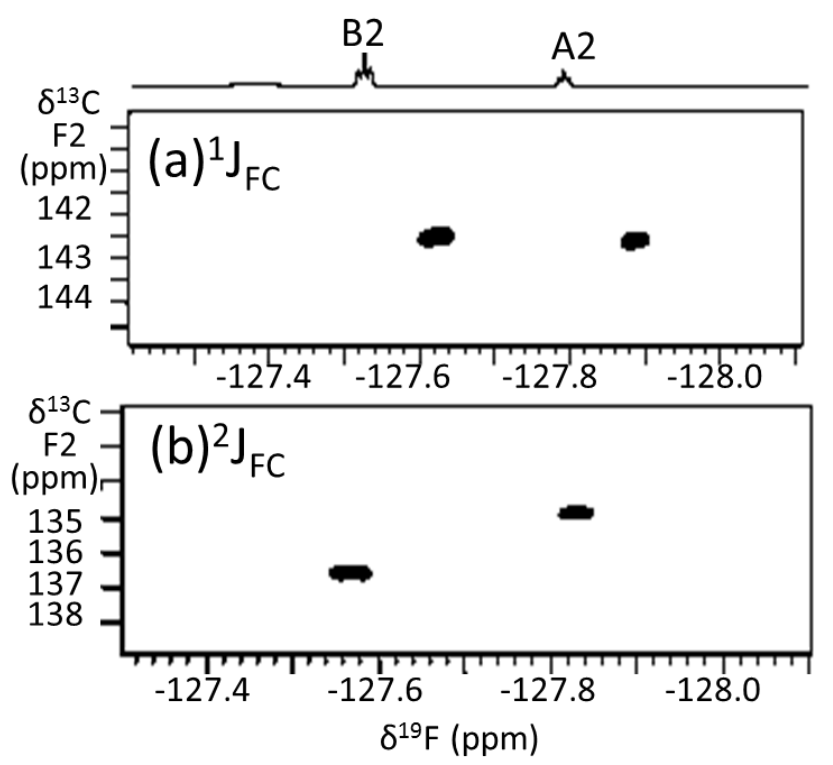

Figure 27. Selected regions from the $470 \mathrm{MHz}$ (a) ${ }^{1} \mathrm{~J}_{\mathrm{FC}}$ and (b) ${ }^{2} \mathrm{~J}_{\mathrm{FC}}$ gHSQC NMR spectra of perfluoro-2-methylene-4,5-dimethyl-1,3-dioxolane, 5.

In the selective COSY spectrum (Figure 28), it can be seen that the resonances of $=\mathrm{CF}_{2}$ fluorine atoms $(\mathrm{A} 2 / \mathrm{B} 2)$ are correlated with resonances in the $\mathrm{CF}$ region $(\mathrm{A} 1 / \mathrm{B} 1)$. Furthermore, the resonance of both A1 and B1 are also correlated with the resonances in $\mathrm{CF}_{3}$ region. Likewise, in Figure 29 the two resonances in $\mathrm{CF}_{3}$ region $(\mathrm{A} 3 / \mathrm{B} 3)$ are correlated with CF resonances (A1/B1). In this way, two sets of resonances, one set for each isomer, were identified and are labeled in Figure 30. 


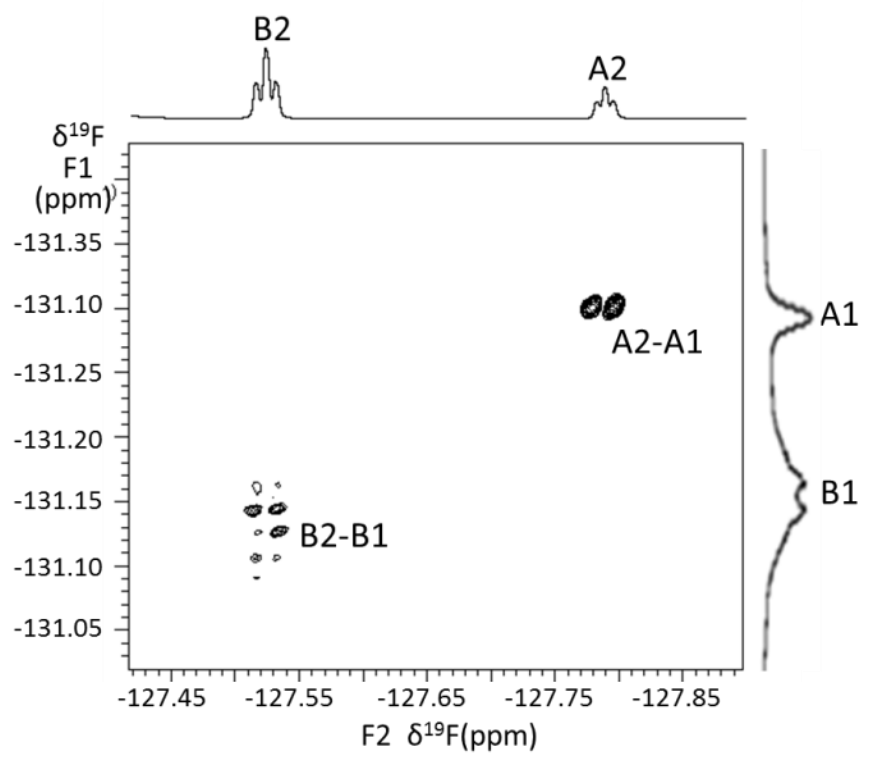

Figure 28. Correlations between the $\mathrm{CF}_{2}$ and $\mathrm{CF}$ regions of the $470 \mathrm{MHz}{ }^{19} \mathrm{~F}^{19}{ }^{19}$ selective COSY 2D-NMR spectrum of perfluoro-2-methylene-4,5-dimethyl-1,3-dioxolane, $\mathbf{5}$.

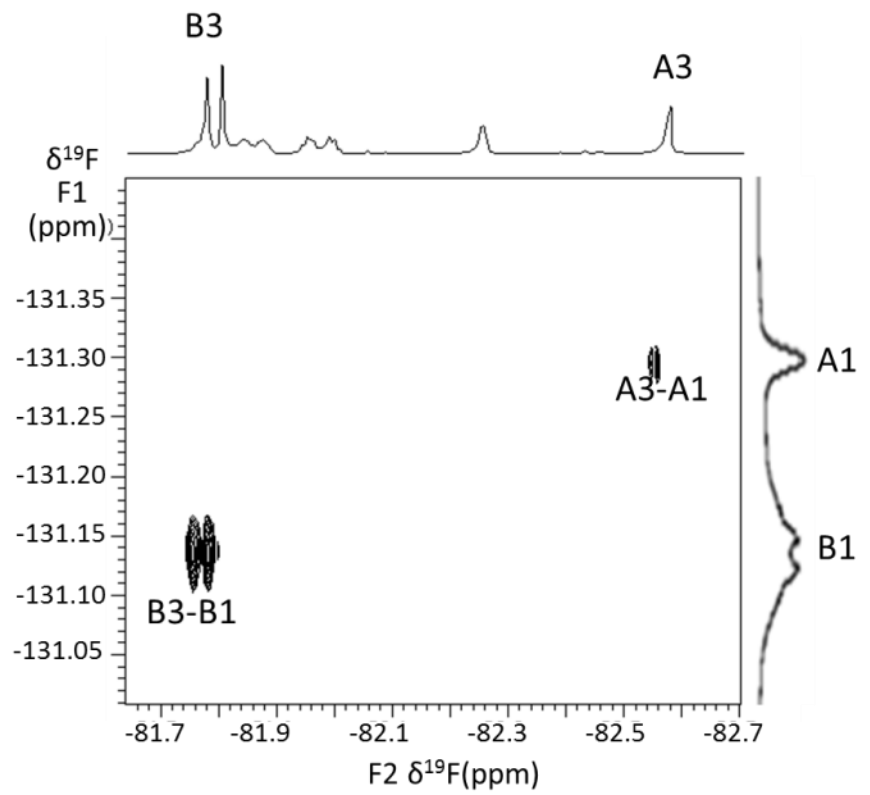

Figure 29. Correlations between the $\mathrm{CF}_{3}$ and $\mathrm{CF}$ regions of the $470 \mathrm{MHz}{ }^{19} \mathrm{~F}^{19}{ }^{19}$ selective COSY 2D-NMR spectra of perfluoro-2-methylene-4,5-dimethyl-1,3-dioxolane, $\mathbf{5}$. 

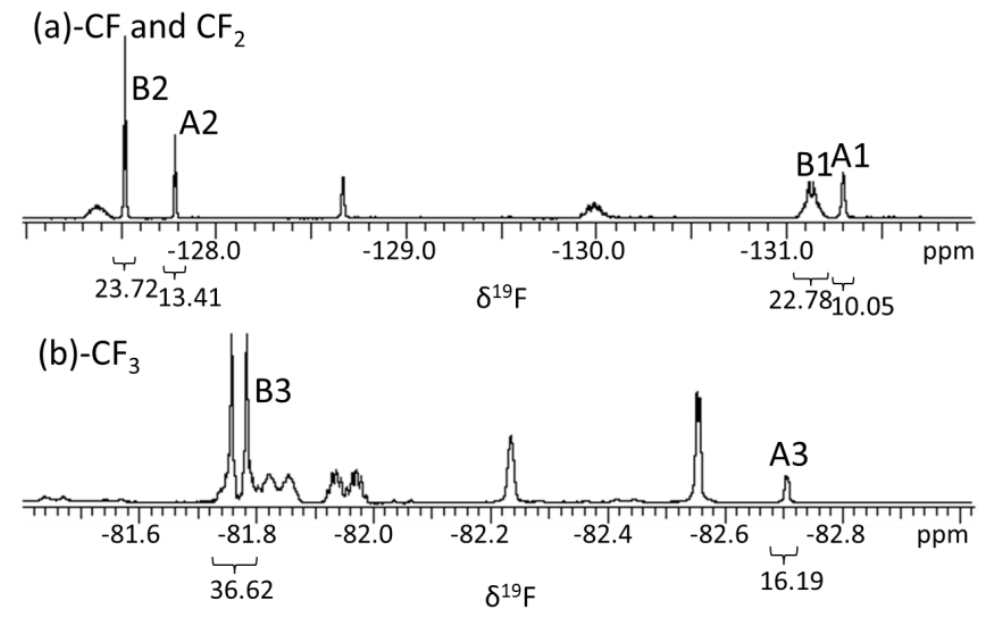

Figure 30. Selected regions from the $470 \mathrm{MHz}{ }^{19} \mathrm{~F}$ 1D-NMR spectrum of perfluoro-2methylene-4,5-dimethyl-1,3-dioxolane (5) showing: (a) the $\mathrm{CF}_{2} / \mathrm{CF}$ region, and (b) the $\mathrm{CF}_{3}$ region.

Because the $\mathrm{CF}$ fluorines in trans isomer are equivalent (as are the two $\mathrm{CF}$ fluorine atoms in the cis isomer); the two isomers cannot be distinguished from each other simply based on COSY and NOESY data as in the previous two intermediates. Taking a closer look at the trans isomer, $\mathrm{CF}$ fluorine and the $\mathrm{CF}_{3}$ group attached to different carbons are on the same side of the ring. ${ }^{50}$ Their ${ }^{4} \mathrm{~J}_{\mathrm{FF}}$ couplings will produce a more complicated and broadened NMR signal for the B1 fluorine. In addition, based on the characterization of previous perfluorinated compound, $\mathbf{4}$, it is observed that the trans configuration is the major component. Therefore, it is concluded that B1, B2, and B3 are attributed to the trans isomer (isomer $\mathbf{5 b}$ ).

One- and two-bond ${ }^{19} \mathrm{~F}-{ }^{13} \mathrm{C}$ gHSQC NMR spectra can further confirm these assignments. In Figure 31, it can be observed that the ${ }^{19} \mathrm{~F}$ resonance of A1 is correlated 
with the ${ }^{13} \mathrm{C}$ resonance of $\mathrm{A} 3$, and vice versa. Similar correlation is also seen for isomer $5 \mathbf{b}$.

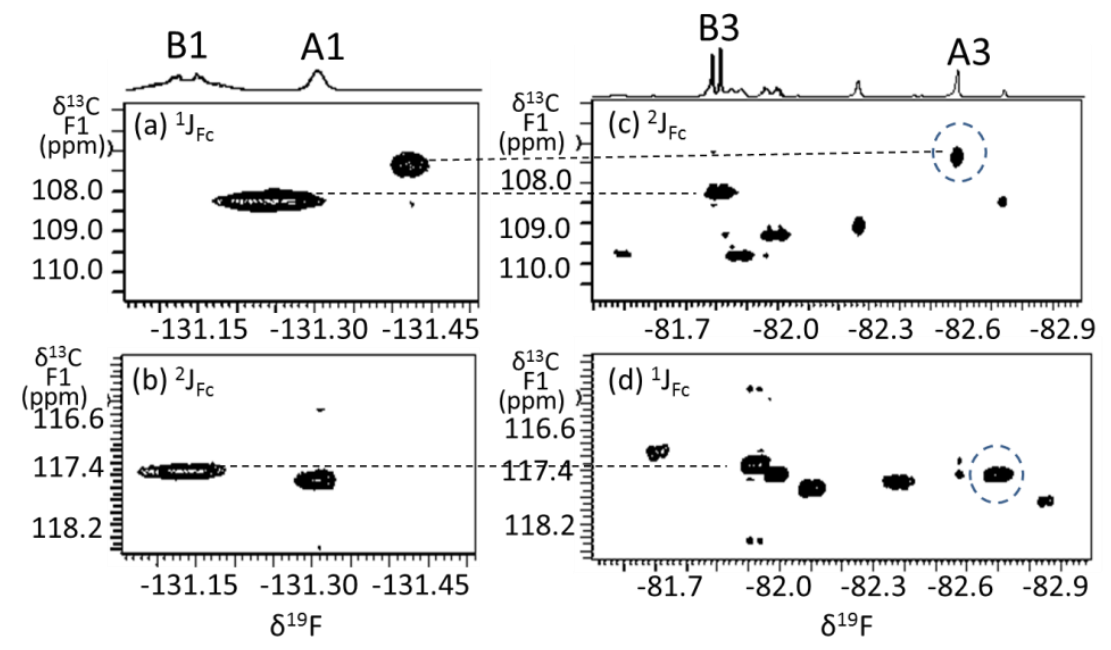

Figure 31. Selected regions from the $470 \mathrm{MHz}(\mathrm{a}, \mathrm{c}){ }^{1} \mathrm{~J}_{\mathrm{FC}}$, and $(\mathrm{b}, \mathrm{d}){ }^{2} \mathrm{~J}_{\mathrm{FC}}$ gHSQC $2 \mathrm{D}-$ NMR spectra of perfluoro-2-methylene-4,5-dimethyl-1,3-dioxolane (5).

Quantitative ${ }^{19} \mathrm{~F}$ NMR can also be used to help confirm some of the previous assignments. If previous assignments are correct, the ratios of B1/A1, B2/A2, and B3/A3 should be equal. From the quantitative ${ }^{19} \mathrm{~F}$ 1D-NMR spectrum, the integrals for the $-\mathrm{CF}$ resonances are in good agreement with those of the $=\mathrm{CF}_{2}$ and $-\mathrm{CF}_{3}$ groups. Therefore, the ratio of the two isomers $\mathbf{5 b}$ : $5 \mathbf{a}$ is $2.27: 1$ (5a $69.4 \%$ trans, $\mathbf{5 b} 30.6 \%$ cis). 
Table 3. Summary of chemical shift assignments for $\mathbf{5}$

\begin{tabular}{rrrr}
\hline & $\mathrm{CFO}$ & $\mathrm{CF}_{3}$ & $\mathrm{CF}_{2}=\mathrm{C}$ \\
\hline${ }^{19} \mathrm{~F}$ chemical shifts & $\mathrm{A} 1:-131.30(\mathrm{~s}) ;$ & $\mathrm{A} 3:-83.35(\mathrm{~m})$ & $\mathrm{A} 2: 127.79(\mathrm{t}) ;$ \\
& $\mathrm{B} 1:-131.13(\mathrm{~d}, \mathrm{~m})$. & $\mathrm{B} 3:-81.78(\mathrm{~d})$ & $\mathrm{B} 2: 127.52(\mathrm{t}) ;$ \\
${ }^{13} \mathrm{C}$ chemical shifts & $\mathrm{A} 1: 107.25 ;$ & $\mathrm{A} 3: 117.43 ;$ & $\mathrm{A} 2: 142.38,134.77(=\mathbf{C}) ;$ \\
& $\mathrm{B} 1: 108.20$. & $\mathrm{B} 3: 117.27$. & $\mathrm{B} 2: 142.49,136.48(=\mathrm{C})$ \\
\hline
\end{tabular}

The fluorine chemical shifts are based on the ${ }^{19} \mathrm{~F}$ 1D-NMR spectrum. The carbon chemical shifts are based on one bond and two bond HSQC 2D-NMR experiments.

\subsection{Conclusions}

Perfluorinated monomer perfluoro-2-methylene-4,5-dimethyl-1,3-dioxolane (5), perfluoro-2,4,5-trimethyl-1,3-dioxolane-2-carboxylic acid (4) and their hydrocarbon precursor methyl-2,4,5-trimethyl-1,3-dioxolane-2-carboxylate (3) were studied using both 1D- and 2D-NMR experiments. The selective versions of COSY and NOESY experiments were collected to confirm the structures of fluorinated compounds. Modified 2D-HSQC spectra were collected to provide information on target regions containing one-bond and two-bond fluorine carbon correlations from 4 and 5. An HMBC experiment was performed to obtain the linkage information of proton and carbon correlations from $\mathbf{3}$. Unambiguous resonance assignments were made, ratios among different isomers were calculated based on the quantitative 1D-NMR spectra.

Methyl-2,4,5-trimethyl-1,3-dioxolane-2-carboxylate (3) prepared by condensation of methyl pyruvate with 2,3-butanediol contains $78.6 \%$ cis isomers ( $\mathrm{S}, \mathrm{R}$ and $\mathrm{S}, \mathrm{R}$ meso, 3a and $\mathbf{3 b}$ isomers) and $21.4 \%$ trans isomers (R,R and $\mathrm{S}, \mathrm{S}$ enantiomers, 3c). Perfluoro2,4,5-trimethyl-1,3-dioxolane-2-carboxylic acid (4) was prepared by controlled 
fluorination of hydrocarbon precursor (3) by fluorine diluted with nitrogen in a perfluorinated solvent and contains $27.2 \%$ cis isomers ( $\mathrm{S}, \mathrm{R}$ and $\mathrm{S}, \mathrm{R}$ meso, $\mathbf{4 a}, \mathbf{4 b}$ isomers) and $72.7 \%$ trans (R,R and S,S enantiomers, $4 \mathbf{c})$. Configurational compositions of $\mathbf{3}$ and $\mathbf{4}$ support the supposition that this fluorination has characteristics of a free radical process.

The decarboxylation reaction of $\mathbf{4}$ to produce $\mathbf{5}$ proceeds fundamentally on the carbon in the 2-position and does not change the configuration of carbon atoms in the 4 and 5 positions. Therefore, the contents of cis and trans isomers are nearly the same in perfluoro-2,4,5-trimethyl-1,3-dioxolane-2-carboxylic acid (4) and monomer perfluoro-2methylene-4,5-dimethyl-1,3-dioxolane (5).

This work illustrates the utility of new/selective variations of COSY, NOESY and HSQC 2D-NMR experiments for charactering fluorinated materials. 


\section{REFERENCES}

1 Rinaldi, P. L. Progress in Nuclear Magnetic Resonance Spectroscopy, 1982, 15, 291.

2 Wuthrich, K. Les Prix Nobel 2002. Almquist and Wikesell International, Stockholm, Sweden, 2003, 235.

3 Cheng, H. N. Chemical Analysis (New York, NY, United States), 1991, 113(Mod. Methods Polym. Charact.), 409.

4 Rinaldi, P. L.; Baughman, J.; Li, L.; Li, X.; McCord, E. F.; Paudel, L.; Twum, E.; Wyzgoski, F.; Zhang, B. Encylopedia of Magnetic Resonance, 2012, in press.

5 Broeren, M. A. C.; Waal, B. F. M. de; Genderen, M.H.P. van; Sanders, H. M. H. F.; Fytas, G.; Meijer, E. W. J. Am. Chem. Soc. 2005, 127, 10334.

6 Chai, M.; Niu, Y.; Youngs, W. J.; Rinaldi, P. L. J. Am. Chem. Soc., 2001, 123, 4670.

7 Claridge, T. D. W. "High-Resolution NMR Techniques in Organic Chemistry", Tetrahederon Organic Chemistry Series, 1999, 19, 13.

8 Morris, G. A.; Freeman, R. J. Am. Chem. Soc., 1979, 101, 760.

9 Patt, S. L.; Shoolery, J.N. J. Magn. Reson., 1982, 46, 535.

10 Ollerenshaw, J.; Nakashima, T. T.; McClung, R. E. D. Magn. Reson. Chem., 1998, 36, 445.

11 Doddrell, D. M.; Pegg, D. T.; Bendall, M. R. J. Magn. Reson., 1982, 48, 323.

12 Stonehouse, J.; Adell, P.; Keeler, J.; Shaka, A. J. J. Am. Chem. Soc., 1994, 116, 6037.

13 Bodenhausen, G.; Ruben, D. J. Chemical Physics Letters, 1980, 69, 185.

14 Li, L., Rinaldi, P. L., Macromolecules, 1997, 30, 520. 
15 Twum, E. B.; Gao, C.; Li, X.; McCord, E. F.; Fox, P. A.; Lyons, D. F.; Rinaldi, P. L. Macromolecules, 2012, 45, 5501.

16 Bodenhausen, G.; Freeman, R.; Niedermeyer, R.; Turner, D. L. J. Magn.Reson., 1977, $26,133$.

17 Bachman, P.; Aue, W. P.; Muller, L.; Ernst, R. R. J.Magn. Reson., 1977, 28, 29.

18 Braunschweiler, L.; Ernst, R. R. J. Magn. Reson. 1983, 53, 521.

19 Ernst, R. R.; Bodenhausen, B.; Wokaun, A. "Principles of Nuclear Magnetic Resonances in One or Two Dimesnions", Oxford University Press, 1992.

20 Kumar, A.; Wagner, G.; Ernst, R. R.; Wüthrich, K. J. Am. Chem. Soc., 1981, 103, 3654.

21 Müller, L. J. Am. Chem. Soc. 1979, 101, 4481.

22 Kogler, H.; Sørensen, O. W.; Bodenhausen, G.; Ernst, R. R. J. Magn. Reson., 1983, 55, 157.

23 Rinaldi, P. L.; Monwar, M. 2D-NMR Methods, in Encyclopedia of Spectroscopy and Spectrometry. Elsevier, 2010.

24 Li, X.; McCord, E. F.; Baiagern, S.; Fox, P.; Howell, J. L.; Sahoo, S. K.; Rinaldi, P. L. Magn Reson Chem, 2010, 49, 413.

25 Resnick, P. R.; Buck, W. H. in J. Scheirs (Ed.), "Modern Fluoropolymers", John Wiley and Sons, 1997.

26 Resnick, P. R. US Pat 3,978,030 (August 31, 1976).

27 Squire, E. N. US Pat 4,530,569 (July 23, 1985).

28 Nakamura, M.; Kaneko, I.; Oharu, K.; Kojima, G.; Matsuo, M.; Samejima, S.; Kamba, M. US Pat 4,897,457 (1990).

29 IGIC, Inc. Staff; Bliss, J. "Plastic Optical Fibers and Applications", Information Gatekeepers Inc, 1994.

30 Okamoto, Y.; Tang, H.; Chemistry Today, 2009, 27, 46.

31 Liu, W.; Koike, Y.; Okamoto, Y. Macromolecules, 2005, 38, 9466. 
32 Mikeš, F.; Yang, Y.; Teraoka, I.; Ishigure, T.; Koike, Y.; Okamoto,Y. Macromolecules, 2005, 38, 4237.

33 Battiste, J. L.; Jing, N.; Newmark, R. A. J. Fluorine Chem., 2004, 125, 1331.

34 Wormald, P.; Ameduri, B.; Harris, R. K.; Hazendonk, P. Polymer, 2008, 49, 3629.

35 Newmark, R. A.; Webb; R. J. J. Fluorine Chem. 2005, 126, 355.

36 Bax, A.; Griffey, R. H.; Hawkins, B. L. J. Magn. Reson. 1983, 55, 301.

37 Rinaldi, P. L.; Li, X.; Li, L.; Paudel, L.; Twum, E. B. in Polymer Science: A Comprehen-sive Reference, Eds. Matyjaszewski, K. and Möller, M., Elsevier BV, 2012, Vol. 2, 111.

38 Suzuki, T.; Yamamoto, K. Reports Res. Lab. Asahi Glass Co., Ltd., 2005, 55.

39 Vuister, G. W.; Boelens, R.; Kaptein, R.; Hurd, R. E.; John, B.; Zijl, P. C. M. van. J. Am. Chem. Soc. 1991, 113, 9688.

40 States, D. J.; Haberkorn, R. A.; Ruben, D. J. J. Magn. Reson., 1982, 48, 286.

41 Kupce, E.; Freeman, R. J. Magn. Reson. Ser A, 1995, 115, 273.

42 Farinies, M.; Soulier, J.; Soulier, R. Bull. Soc. Chim. Fr., 1972, 3, 1066.

43 Flad, G.; Sabourin, R.; Chovin, P. Bull. Soc. Chim,. 1975, Fr.5-6, 1347.

44 Schmidt, M.; Ungvari, J.; Glode, J.; Dobner, B.; Langner, A.; Bioorg. Med. Chem., 2007, 15, 2283.

45 Lagow, R. J.; Bierschenk, T. R.; Juhlke, T. J.; Kawa, H. Chapter 5, pp. 97-125 in Synthetic Fluorine Chemistry, Ed. Olah, G.A.; Chambers, R. C.; Prakash, G. A. S. John Wiley Sons, New York, 1992.

46 Miller, W. T.; Koch, S. D. Jr. J. Am. Chem. Soc., 1957, 79, 3084.

47 Rozen, S. Acc. Chem. Res., 1988, 21, 307.

48 Wimperis, S.; Freeman, R. J. J. Magn. Reson., 1984, 58, 348.

49 Li, X; McCord, E. F.; Fox, P. A.; Howell, J. L.; Rinaldi, P. L. Int. J. Polym. Anal. Charact., 2012, 17, 161. 
50 Battiste, J. L.; Newmark, R. A. Prog. In NMR Spectroscopy, 2006, 48, 1. 